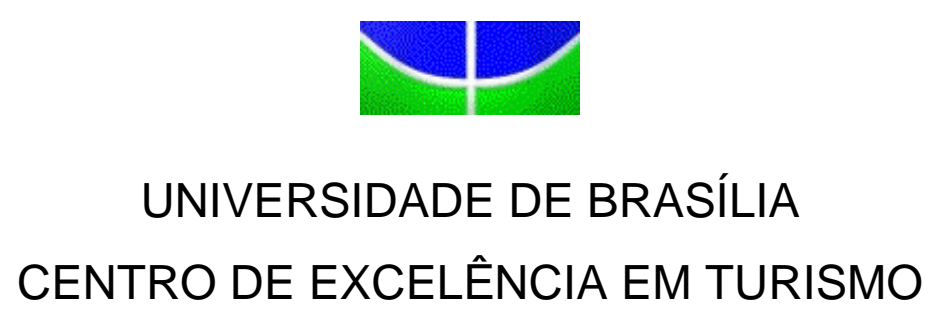

PANORAMA DE RESTAURANTES DO TIPO NATURAL NA CIDADE DE BRASÍLIA/DF

NELI DE ALARCÃO ROMEIRO

Brasília/DF

Dezembro de 2003. 
R763 Romeiro, Neli de Alarcão

Panorama de restaurantes do tipo natural / Neli de Alarcão Romeiro - Brasília, 2003.

53 f.: il.

Orientadora: Wilma M.C. Araújo.

Monografia (Especialização) - Universidade de Brasília. Centro de Excelância em Turismo.

Bibliografia: f. 36-37 (53 f.)

1. Turismo. 2.Gastronomia. 3. Restaurantes Naturais - Monografia. I. Título. 


\author{
UNIVERSIDADE DE BRASÍLIA \\ CENTRO DE EXCELÊNCIA EM TURISMO \\ CURSO DE ESPECIALIZAÇÃO EM GESTÃO DA HOSPITALIDADE
}

\title{
PANORAMA DE RESTAURANTES DO TIPO NATURAL NA CIDADE DE BRASÍLIA/DF
}

NELI DE ALARCÃO ROMEIRO

Monografia apresentada ao Centro de Excelência em Turismo da Universidade de Brasília como requisito para obtenção do certificado de especialização em "Gestão da Hospitalidade".

WILMA MARIA COELHO ARAÚJO

Doutora em Tecnologia de Alimentos

Brasília,DF

Dezembro de 2003 


\section{AGRADECIMENTOS}

\section{A DEUS}

"Você se fez presente em todos os momentos firmes e trêmulos.

E, passo a passo, pude sentir a sua mão na minha, transmitindo-me a segurança necessária para enfrentar meu caminho e seguir...

Sua presença é qualquer coisa como a luz e a vida, e sinto que, em meu gesto, existe o Seu gesto, em minha voz a Sua voz."

(Vinicius de Morais)

\section{A MINHA FAMÍLIA,}

Pelo apoio incondicional e pela compreensão dos meus momentos de ausência e falta de tempo para me dedicar aos assuntos e afazeres domésticos.

Recebam o reconhecimento e a lembrança de que juntos compartilhamos o mérito desta conquista.

\section{AOS MESTRES}

Que nos transmitiram seus conhecimentos e experiências, foram amigos, nos compreenderam e nos incentivaram a olhar firme para o nosso objetivo, a transpor todos os obstáculos e a lutar pelo nosso ideal.

Meus agradecimentos especiais para a Doutora Wilma Araújo, pelo interesse nas discussões e excelente orientação na organização deste trabalho.

Deixo registrada minha sincera gratidão, meu respeito e profunda admiração pelo exemplo de profissionalismo que me foi transmitido.

\section{AOS FUNCIONÁRIOS}

Força viva do CET, pela dedicação e constante busca da excelência no atendimento aos alunos. 
"A palavra "progresso" não terá qualquer sentido enquanto houver crianças infelizes".

Eisntein, Albert 


\section{RESUMO}

A busca constante por alimentos saudáveis, como forma de preservação da saúde, tem aumentado a cada dia, direcionando os consumidores para os restaurantes especializados em gastronomia do tipo natural.

Esse cenário motivou a investigação de restaurantes desse tipo, sobre os parâmetros de qualidade e aplicação da legislação vigente, que regulamenta os procedimentos para preparação e comercialização de alimentos.

Trata-se de trabalho, de caráter exploratório-descritivo, tendo sido desenvolvido mediante pesquisa realizada junto a 8 restaurantes, localizados no Plano Piloto, Brasília/DF, que oferecem comida do tipo natural.

Tomou-se como base a literatura legal relacionada com a segurança alimentar com aplicação direta da lista de verificação das Boas Práticas Fabricação em Estabelecimento da Área de Alimentos, da Agência Nacional de Vigilância Sanitária (ANVISA,.2002).

Não obstante a existência de responsabilidade civil sobre a produção de alimentos, o resultado do trabalho evidenciou prática dissociada do cumprimento dos dispositivos legais.

Palavras chaves: Gastronomia natural; segurança alimentar; responsabilidade social, dispositivo legal. 


\section{ABSTRACT}

The constant search for healthy foods, as a way of health preservation, has been increasing every day and has been driving consumers to restaurants specialized in natural gastronomy .

This scenery has motivated the investigation of natural restaurant, about quality parameters and law application that rules the procedures to prepare and to market foods.

This work has an exploration-descriptive character and has developed research in 8 restaurants located in Brasília (DF), which offers natural foods.

The work was based on the legal literature related to food safety with direct application of the "Good Manufacturing Practices Check List (ANVISA, 2002)".

Although having civil responsibility for foods production, the result of this work has shown that the restaurants do not match legal demands.

Key words: Natural gastronomy; food safety; social responsibility, legal tool. 
SUMÁRIO

1 - EMPREENDIMENTOS GASTRONÔMICOS

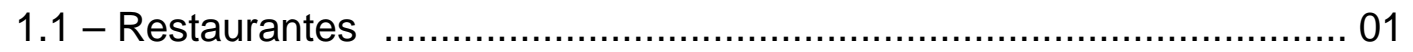

1.1.1 - Administração de Restaurantes ............................................... 06

1.1 .2 - Móveis, Equipamentos e Utensílios ........................................ 07

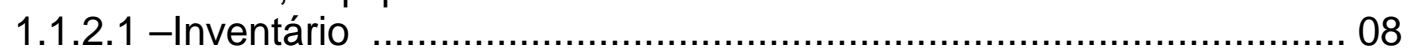

1.1.1.2 - Quadro de Pessoal........................................................... 09

1.2 - Restaurantes Naturais ......................................................... 12

2 - PROCEDIMENTOS OPERACIONAIS EM EMPREENDIMENTOS

GASTRONÔMICOS ........................................................... 15

3 - PANORAMA DE RESTAURANTES DO TIPO NATURAL EM

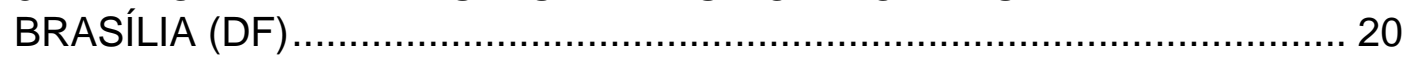

3.1 - Panorama dos Empreendimentos Gastronômicos .......................... 20

3.2 - Perfil Higiênico-Sanitário dos Empreendimentos Gastronômico......... 23

3.2.1 - Situação e Condições da Edificação e Instalações .......................... 23

3.2.2 - Equipamentos Móveis e Utensílios .............................................. 26

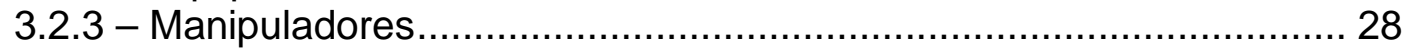

3.2.4 - Fluxo de Produção (Produção e Transporte do Alimento.................. 29

3.2.5 - Programa de Controle de Qualidade (Documentação) .................... 30

4 - CONCLUSÕES E CONSIDERAÇÕES FINAIS .............................. 31

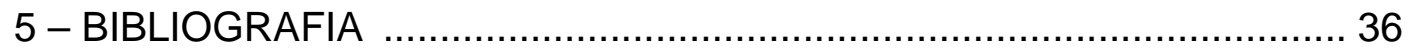

6 - LISTA DE TABELAS:

6.1 - Tabela 1 - Tipos de Restaurantes Comerciais ................................ 04

6.2 - Tabela 2 - Tipos de Serv. Oferecidos Em Restaurantes Comerciais . 05

6.3 - Tabela 3 - Relação de Alguns Utens; de Utilização em Restaurantes 08

6.4 - Tabela 4 - Níveis de Paridade de Inventários ............................... 09

6.5 - Tabela 5 - Funções Atualmente Existente em Algumas Cozinhas .... 11

6.6 - Tabela 6 - Conteúdo de Fibras Alimentares em Alguns Produtos de

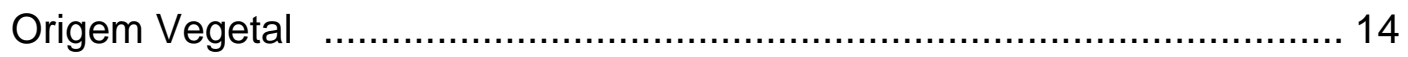


6.7 - Tabela 7 - Edifícios e Instalações ............................................... 23

6.8 - Tabela 8 - Equipamentos, Móveis e Utensílios .................................. 26

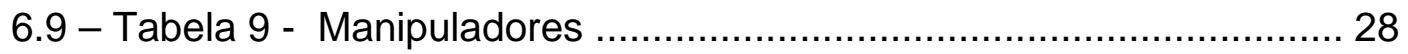

6.10 - Tabela 10 - Fluxo de Produção (Produção e Transporte do

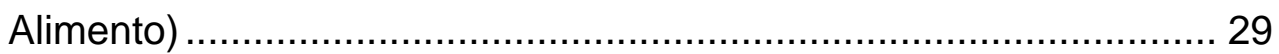

6.11 - Tabela 11 - Programa de Controle de Qualidade (Documentação) 30

7. ANEXO:

7.1 - Lista de Verificação das Boas Práticas de Fabricação 38

8. APÊNDICES:

8.1 - Questionário de Levantamento de Dados ....................................... 46

8.2 - Tabulação dos Dados Coletados .................................................. 48

8.3 - Classificação dos Restaurantes Pesquisados ................................ 52 


\section{INTRODUÇÃO}

Este trabalho foi elaborado no sentido concluir as atividades do curso de Especialiazação em "Gestão da Hospitalidade", realizado pelo Centro de Excelência em Turismo, da Universidade de Brasília - CET/UnB.

Nele foram abordadas questões relativas a utilização da literatura legal relacionada com a segurança alimentar com aplicação direta da lista de verificação das Boas Práticas de Fabricação em Estabelecimento da Área de Alimentos, da Agência Nacional de Vigilância Sanitária (ANVISA), 2002).

Trata-se de estudo de carater exploratório-descritivo, realizado junto a restaurantes que oferecem comida do tipo natural $\mathrm{I}^{1}$, localizados no Plano Piloto, Brasília/DF, com o objetivo de virificar o panorama de empreendimentos dessa natureza sob o aspecto da segurança alimentar, estabelecendo um paralelo entre a prática dos proprietários e a afimação da literatura e da legislação pertinentes.

Os restaurantes visitados, num total de 8, localizados no Plano Piloto, Brasília/DF, foram escolhidas observando-se a disponibilidade dos respectivos responsáveis. Os dados foram coletados no mês de outubro e novembro de 2003 , especificamente na última semana de outubro e a primeira de novembro.

Utilizou-se um questionário como instrumento na coleta dos dados, para verificar o panorama dos estabelecimentos já mencionados, o qual consta do apêndice 1. Mais importante foi a utilização da Lista de Verificação das Boas Práticas de Fabrica-

\footnotetext{
${ }^{1}$ Empreendimentos que fornecem comida natural.
} 
ção em Estabelecimentos da Área de Alimentos da Agência Nacional de Vigilância sanitária (ANVISA, 2002), anexo 1, para avaliar a adequação desses estabelecimentos quanto à segurança alimentar. Registre-se que assinalou-se "sim (S)" para os itens atendidos, "não (N)" para os itens não atendidos e "não aplicável (NA)" para itens não aplicáveis. Foram avaliados:

- Bloco 1 : Edificação e Instalações

- Bloco 2 : Equipamentos, móveis e utensílios

- Bloco 3 : Manipuladores

- Bloco 4 : Fluxo de Produção (Produção e Transporte do alimento)

- Bloco 5 : Programa de Controle de Qualidade (Documentação)

Para efeito de apresentação do trabalho o texto foi dividido em 4 capítulos, assim definidos:

- Capítulo 1: Empreendimentos Gastronômicos

- Capítulo 2: Procedimentos Operacionais em Empreendimentos Gastronômicos

- Capítulo 3: Panorama de Restaurantes do Tipo Natural no Plano Piloto, Brasília (DF)

- Capítulo 4: Conclusões e Considerações Finais 


\title{
Capítulo 1
}

\begin{abstract}
"A menos que os médicos de hoje tornem-se os dietistas de amanhã, os dietistas de hoje se tornarão os médicos de amanhã".

Alexis Carrel, ganhador do Prêmio Nobel (1935)
\end{abstract}

\section{EMPREENDIMENTOS GASTRONÔMICOS}

\section{1 - Restaurantes}

Data de 1765 o início da venda de alimento preparado, quando o Francês A.Boulanger, um vendedor ambulante de sopas, se estabeleceu comercialmente próximo ao Louvre para vender caldos restauradores. Daí a denominação "restaurante", que vem do latim "restaurare" (restaurar) ${ }^{1}$, no sentido de restabelecer o vigor físico, de reparar o bom estado físico ou recuperar as forças. Restaurante significa também lugar onde comida e bebida podem ser encontrados, mediante pagamento.

Após a idade média, os vendedores ambulantes na Europa Ocidental, ocuparam papel significativo para a expansão do mercado vendendo as mais diferentes e exóticas mercadorias. Nesse sentido, Monsieur Boulanger que vendia sopa de porta em porta, foi um inovador(Mazzoli, Mentore - 1978).

$\mathrm{Na}$ França, os nomes de família, tem suas origens na profissão ou local de origem da família. "Boulanger", na lingua francesa, siginifica"padeiro". Tudo leva a crer que Monsieur Boulanger fazia honrar seus antepassados, pois ainda hoje, é impensável uma refeição na França, sem acompanhamento de um bom pão, principalmente quando se trata de sopa.

\footnotetext{
${ }^{1}$ Em latim (restaurar) significa restabelecer o vigor físico, reparar o bom estado físico ou recuperar as forças.
} 
Acredita-se que o sucesso alcançado e perpetuado por Boulanger, se devia a arte de servir refeição quente acompanhada de um pão preparado simultaneamente. Àquela época, o principal prato servido era uma "sopa de coxa de carneiro ao molho branco" (Mazzoli, Mentore - 1978).

O restaurante de Boulanger foi provavelmente o primeiro lugar público onde se podia solicitar uma refeição a partir de um "menu". A primeira cafeteria de que se tem notícia, a "Kiva Han", foi inaugurada em Constatinopla no ano de 1475, logo após a tomada da cidade pelos Turcos Otomanos, em 1453, que determinou o fim do Império Bizantino e do período Medieval (Mazzoli, Mentore- 1978).

Os serviços de alimentação podem ser divididos em três fases: A primeira, que prevaleceu até a década de 50, consistia em estabelecimentos com estrutura familiar, prática que prevalece até os dias atuais. Caracterizam-se, também, pela prática de serviços personalizados.

A Segunda fase ocorreu simultaneamente com a expansão dos grande centros urbanos. Caracterizaram-se pela implantação de restaurantes comerciais, pela rápida expansão das lanchonetes, pizzarias, etc., mais organizados dando ênfase às estruturas administrativas e operacionais, surgindo as primeiras cadeias ou grupos de lojas.

A terceira e última fase correspondente à década passada, caracterizada pelo enriquecimento do profissionalismo e pela chegada das grandes multinacionais do setor, influenciando na implantação do sistema de "Ticket Restaurante, administradoras de restaurantes, lanchonetes do tipo fast food, etc...", contribuindo para o aumento salutar da concorrência e despertando o consumidor para os seus direitos, para a exigência na melhoria nos padrões dos serviços, da higiene, da qualidade e dos custos (Antônio Romão A Silva FiIho, 1996). 
Montar um restaurante é dotar um espaço físico escolhido de instalações apropriadas, criando uma infra-estrutura funcional com água, esgoto, ar condicionado, eletricidade, ventilação e exaustão, equipamentos, materiais, utensílios, móveis, etc. Alexandre Lobo - 1999, classifica os restaurantes comerciais e os tipos de serviço de acordo com as tabelas 1 e 2. 
TABELA 1 - TIPOS DE RESTAURANTES COMERCIAIS

\begin{tabular}{|c|c|}
\hline CLASSIFICAÇÃO & DESCRIÇÃO \\
\hline $1^{a}$ Categoria & Atendimento requintado, oferecem geralmente refeições a "la carte" e pessoal qualificado \\
\hline Típicos (Regionais) & $\begin{array}{l}\text { Caracterizam-se pela cozinha específica, para definir a respectiva decoração e uniforme dos funcionários, inspiram-se na região na } \\
\text { qual foi idealizado. }\end{array}$ \\
\hline Grill-Room & $\begin{array}{l}\text { Especializados em grelhados e flambados, de preferência preparados à vista do cliente . Requerem equipamentos específicos como } \\
\text { Grill e Rechaud, frigideira e aparelho de fondue. No serviço utilizam mesas auxiliares (gueridons). Devido a utilização de grelhas exige } \\
\text { uma boa exaustão e ventilação adequada para não criar névoas de gorduras, nem aquecer demasiadamente o ambiente. }\end{array}$ \\
\hline Self-Service & $\begin{array}{l}\text { Caracterizam-se pelo auto-serviço, ou seja, o próprio cliente é que se serve, em uma linha de balcões especiais: aquecidos, refrigera- } \\
\text { dos ou neutros, onde a alimentação é exposta conforme seja sua temperatura, acondicionada em pirex ou recipientes de aço inoxidá- } \\
\text { vel. Pode ou não contar com o auxílio de copeiros. O preço é por pessoa ou por quilo. }\end{array}$ \\
\hline Snak-bar & $\begin{array}{l}\text { Caracterizam-se por serviços rápidos a qualquer hora do dia ou da noite e normalmente localizados em estações de embarque e de- } \\
\text { sembarque de passageiros. Serviço simples parecido com uma lanchonete sofisticada. Geralmente o mobiliário é composto de bal- } \\
\text { cões e bancos altos. }\end{array}$ \\
\hline Scoth-bar & $\begin{array}{l}\text { Caracterizam-se pelo serviço de aperitivos, coquetéis, drinques e petiscos. Funcionam normalmente no interior de restaurantes sofis- } \\
\text { ticados, boates ou em uma ante-sala como ponto de encontro. } \\
\text { Taberna - Caracterizam-se principalmente pela venda de vinhos, assados, pães, etc. }\end{array}$ \\
\hline Pub & $\begin{array}{l}\text { Muito comum na Inglaterra, onde se originaram. Caracterizam-se por possuir dois ambientes, sendo um deles o subsolo. Funcionam } \\
\text { com serviços de bebidas e refeições e com espetáculos de variedades. } \\
\text { Cervejarias - Tem como atração principal a cerveja, entretanto, servem vários tipos de bebidas. Servem tira-gosto como complemento } \\
\text { para a bebida. }\end{array}$ \\
\hline Churrascarias & Especializados em assados e grelhados. A carne normalmente é servida em forma de "rodízio" ou a la carte. Mantém balcão de frios. \\
\hline
\end{tabular}




\begin{tabular}{|l|l|}
\hline House & Especializados nos mais diversos tipos de carne bovina, normalmente acompanhadas de molhos especiais. \\
\hline Fast-Food & $\begin{array}{l}\text { Caracterizam-se pelo serviço ultra-rápido, normalmente direcionado a um público com pouco tempo disponível para refeições. Exigem } \\
\text { equipamentos próprios para a produção rápida sem perda da qualidade. }\end{array}$ \\
\hline
\end{tabular}

TABELA 2 - TIPOS DE SERVIÇOS OFERECIDOS EM RESTAURANTES COMERCIAIS

\begin{tabular}{|l|l|}
\hline \multicolumn{1}{|c|}{ Tipos de Serviços } & \multicolumn{1}{c|}{ CARACTERÍSTICA } \\
\hline À Inglesa (direto) & $\begin{array}{l}\text { O garçom coloca-se com a travessa à esquerda do cliente, e utilizando garfo e colher na mão direita, maneja- } \\
\text { dos em forma de alicate, transfere os alimentos da travessa para o prato à frente do mesmo. }\end{array}$ \\
\hline À Inglesa Indireto & $\begin{array}{l}\text { O garçom apresenta a bandeja ao cliente pelo lado esquerdo. Depois coloca a mesma sobre um carrinho junto } \\
\text { à mesa, ou mesmo num pequeno aparador de apoio próximo, colocando os alimentos em um prato vazio, utili- } \\
\text { do cliente, por trás do mesmo e pelo lado direito. }\end{array}$ \\
\hline À Francesa & $\begin{array}{l}\text { A bandeja de alimentos é colocada sobre a mesa, o mais próximo possível dos pratos dos clientes, e estes } \\
\text { servem-se a gosto. }\end{array}$ \\
\hline À Americana & O cliente recebe o prato já pronto, sendo sempre colocado à sua frente, pela direita. \\
\hline Buffet (Self-Service) & $\begin{array}{l}\text { Os cliente servem-se de uma mesa, ou de balcões com pratos frios e quentes, molhos e complementos, onde } \\
\text { encontram variedade e opções. Esse sistema atualmente é muito utilizado. }\end{array}$ \\
\hline
\end{tabular}

(1999 - Lôbo, Alexandre - Manual de Estrutura e Organização do Restaurante Comercial) 


\subsection{1 - Administração de Restaurantes}

A organização e administração do restaurante é de fundamental importância para garantir o funcionamento do mesmo de forma a oferecer serviços de excelente qualidade. A administração, a exemplo de qualquer outra empresa, deve respeitar as normas básicas de estrutura e organização a fim de obter a melhor produtividade e a eficácia necessária para alcançar os resultados desejados. Atenção especial deve ser dispensada à administração dos recursos humanos de forma a manter permanente motivação da equipe e determinação na busca constante da excelência no atendimento, verificando o grau de satisfação do cliente.

Os itens constantes do quadro abaixo representam alvos estratégicos e devem ser estudados e providenciados com muita atenção para que não haja atropelo no desenvolvimento das atividades de atendimento à clientela (Antônio Romão A Silva Filho, 1996).

PROCESSOS-CHAVE NA ADMINISTRAÇÃO DE UM RESTAURANTE:

\begin{tabular}{|l|l|}
\hline a) Administração & - Pessoal \\
& - Compras \\
& - Armazenamento (recepção, almoxarifado, câmaras fri- \\
& as, freesers, balcões, e outros) \\
& - Contabilidade \\
& - Finanças (bancos, contas a receber e contas a pagar). \\
& - Controladoria (controles gerais e específicos, caixa \\
& geral, inventários) \\
& - Preventiva \\
\hline b) Manutenção & - Corretiva \\
\hline c) Atividades Operacionais & - Copa \\
& - Cozinha \\
\hline
\end{tabular}




\begin{tabular}{|c|c|}
\hline & $\begin{array}{l}\text { - } \text { Bar } \\
\text { - Caixas } \\
\text { - } \text { Rouparia e lavanderia }\end{array}$ \\
\hline d)Atendimento ao Público & $\begin{array}{l}\text { - } \text { Telefonia } \\
\text { - } \text { Reservas } \\
\text { - Recepção } \\
\text { - } \text { Serviços de portaria } \\
\text { - } \text { Controle de espera }\end{array}$ \\
\hline e) Marketing; Vendas & $\begin{array}{l}\text { - } \text { Administração de marketing } \\
\text { - Pesquisa de mercado } \\
\text { - } \text { Telemarketing } \\
\text { - Promoção de vendas } \\
\text { - } \text { Cadastro de clientes } \\
\text { - } \text { Calendário promocional } \\
\text { - } \text { Mala Direta }\end{array}$ \\
\hline
\end{tabular}

\subsection{2 - Móveis, Equipamentos e Utensílios:}

Independentemente do tipo de restaurante, o garçom é o responsável pela conservação, manutenção e disponibilização para o serviço de um grande número de móveis, equipamentos e utensílios; o treinamento é fundamental ao seu desempenho. Mobiliário, itens de decoração, utensílios variam com o tipo do restaurante (tabela 3). 
TABELA 3:- RELAÇÃO DE ALGUNS UTENSÍLIOS DE UTILIZAÇÃO EM RESTAURANTES (MAZZOLI, MENTORE - 1978)

\begin{tabular}{|l|l|}
\hline \multicolumn{1}{|c|}{ UTENSÍLIO } & \multicolumn{1}{c|}{ UTILIZAÇÃO } \\
\hline Garfo e faca pequena & Faca pequena - caviar, fois-gras \\
Colher de sobremesa & Consummé quente, frio ou geléia. \\
Um garfo de forma especial (com- & Sopas \\
binação de garfo e colher) & Ostras, macarel, cocktail de camarão ou lagosta. \\
Pequena colher & \\
Talher próprio para peixe & Ovos em cocóte. \\
Garfo e colher grandes & peixe, lagosta, camarão frio. \\
Garfo e faca grandes & Massa (farináceos). \\
Garfo pequeno & aves e carnes. \\
Garfo e faca pequenos & Saladas e tortas. \\
& queijo. \\
\hline Objetos de Vidro: & Devem ser tão finos Quanto práticos, particularmente nos restauran- \\
Copos & tes mais sofisticados. \\
\hline
\end{tabular}

\subsubsection{1 - Inventário}

Baseado em sua larga experiência na área de alimentos e bebidas, Davies (2001) indica, na tabela 4, o quantitativo necessário de utensílios para operação de um restaurante. Obviamente, alguns fatores podem alterar essa indicação. A regra básica inclui 3 conjuntos de cada peça, sendo um no restaurante, outro em uso (na máquina de lavar, em trânsito, etc), e um terceiro na reserva (no almoxarifado). 
TABELA 4 - Níveis de Paridade de Inventário ( Davies, 2001)

\begin{tabular}{|l|l|}
\hline \multicolumn{1}{|c|}{ Utensílios } & \multicolumn{1}{c|}{ Quantitativo } \\
\hline Pratos rasos & 2 a 3 vezes o número de lugares \\
\hline Pratos fundos & 2 a 3 vezes o número de lugares \\
\hline Pratos de salada/sobremesa & 3 a 4 vezes o número de lugares \\
\hline Pratos de pão & 3 a 4 vezes o número de lugares \\
\hline Xícaras & 3 a 4 vezes o número de lugares \\
\hline Pires & 3 a 4 vezes o número de lugares \\
\hline Pratos de frutas/lavandas & 2 a 3 vezes o número de lugares \\
\hline Açucareiros & 1 1/2 a 1 vez o número de lugares \\
\hline Copos & 3 dos mais usados para cada lugar (copos de água, vinho branco e vinho tinto) \\
\hline Talheres & 3 conjuntos para cada lugar \\
\hline Guardanapos & 3 para cada lugar \\
\hline Toalhas & Disponibilidade de três para cada mesa \\
\hline Uniformes & Disponibilidade de 3 uniformes completos para cada empregado \\
\hline
\end{tabular}

\section{.1.3 - Quadro de Pessoal:}

A definição do Quadro de Pessoal de um restaurante está diretamente ligada ao tamanho e categoria do mesmo. Além desses, outros fatores são relevantes e devem ser considerados (Alexandre Lobo, 1999):

- Natureza e tipo de serviços oferecidos

- Número de pessoas atendidas

- Sazonalidade

- Recursos financeiros disponíveis

- Dimensão física

- Horário de funcionamento

Em restaurantes pequenos ocorre com freqüência a duplicidade de função. Isso significa que um mesmo empregado exerce mais de uma função. Nos restaurantes que oferecem serviço "self serviçe", a questão do pessoal é mais centrada nas atividades de cozinha e normalmente os auxiliares de cozinha se desdobram no atendimento ao cliente e reposição do balcão térmico. Nesse tipo de restaurante dificilmente há espaço para contratação de "Maitre" , uma espécie de chefe de sala, responsável pela distribuição dos garçons e pelo bom andamento do serviço. 
Para exemplificar, o dimensionamento de um quadro fixo de cozinha, poderá ser encontrado como ponto de referência para o estudo de outros setores, aplicando-se a fórmula a seguir (Alexandre Lôbo - 1999):

Q.L. = número de refeições preparadas por turno $X \mathrm{n}$ minutos

Jornada de trabalho $\times 60$ minutos

Onde:

- Q.L. - Quadro de lotação que visa definir o número de empregados necessários para o trabalho de pré-preparo e preparo de refeições por turno.

- Número total de refeições preparadas por turno (no caso de self serviçe fazer o cálculo da porção média, para que se possa partir da unidade).

- $\mathrm{N}$ minutos = tempo médio despendido para o preparo e serviço de refeição individual.

- $\quad$ Jornada de trabalho = número de horas de trabalho por dia. 
TABELA 5 FUNÇÕES ATUALMENTE EXISTENTES EM ALGUMAS COZINHAS

(Antônio R.S. Filho, 1996)

\begin{tabular}{|c|c|}
\hline EMPREGOS & FUNÇÕES \\
\hline Administrador & Gerenciamento de todos os processos \\
\hline Gerente de Produção & $\begin{array}{l}\text { Responsável pela produção, distribuição das refeições. Apoio na elaboração } \\
\text { de cardápios, requisições, uniformes de empregados. }\end{array}$ \\
\hline Chefe-de-Cozinha - Cozinheiro A & Preparação de carnes, molhos, guarnições. \\
\hline Cozinheiro B & Preparação de guarnições, frituras, forneados. \\
\hline Cozinheiro C & Preparação de acompanhamentos. \\
\hline Auxiliar de Cozinha & Apoio de preparação. \\
\hline Magarefe & Cortes de carnes, porcionamentos. \\
\hline Copeira & $\begin{array}{l}\text { Distribuição e reposição de pratos quentes e frios, preparação de saladas, } \\
\text { sobremesas. } \\
\text { Apoio geral. }\end{array}$ \\
\hline Auxiliar de Serviços Gerais & $\begin{array}{l}\text { Higienização de todos os utensílios da cozinha, refeitórios e dependências } \\
\text { físicas, recolhimento de lixo. } \\
\text { Não cabe ao ASG, a limpeza dos equipamentos e área de trabalho durante a } \\
\text { produção. }\end{array}$ \\
\hline Almoxarife & $\begin{array}{l}\text { Responsável pelo estoque, controle de entrada e saída de mercadorias, } \\
\text { recebimento e conferência de gêneros, notas fiscais, higienização e seleção } \\
\text { quando necessário. }\end{array}$ \\
\hline Auxiliar de almoxarife & Estoca, distribui e armazena. \\
\hline Técnico de Manutenção & Manutenção geral dos equipamentos. \\
\hline Auxiliar de Escritório & Apoio burocrático. \\
\hline Motoristas & Transporte geral. \\
\hline Técnico de Segurança do Trabalho & Responsável pela segurança \\
\hline Caixa & Manuseio de registradoras \\
\hline Encarregado de Higienização & Responsável pela higienização em geral \\
\hline Garçons & Responsáveis pela distribuição nos serviços de mesa. \\
\hline
\end{tabular}

Um aspecto de suma importância que deve ser ressaltado é o treinamento do pessoal. Os programas de treinamento, orientação e acompanhamento visam corrigir distorções ou sanar deficiências de desempenho dos executores. Tais programas constituem parte do planejamento geral do empreendimento, não podendo faltar a previsão e indicação dos meios que possibilitem a melhor utilização dos recursos humano. 
Muitas vezes um restaurante é julgado pela natureza do seu atendimento, dessa forma, é natural que a falta de treinamento ou de orientação eficaz tenha tanta influência nas reações do cliente assim como na sua disposição para retornar ao local.

Grande parte das tarefas de um restaurante são extremamente trabalhosas e requerem treinamento específico, para que os empregados possam executá-las bem e com segurança (Davies, 2001).

Cada tipo de restaurante exige do empreendedor conhecimento específico sobre o funcionamento, para evitar desperdício de tempo, espaço e de recursos materiais e financeiros.

Vale ressaltar a função econômica e social dos restaurantes e seu importante papel na geração de empregos. Em A\&B, a responsabilidade social transcende a obrigação legal quando as empresas selecionam fornecedores de produtos/serviços, considerando princípios éticos, trabalhistas, técnicos, que propiciam a credibilidade da organização com respeito à segurança alimentar e ao desperdício de produtos alimentícios (Wilma M.C.Araújo; Lucianne Cardoso e Lucilene Bentes, 2003).

Nesse setor de alimentação, milhares de brasileiros ganham a vida como empresários atrás do balcão, contribuindo com a geração de empregos. Essa expressão "atrás do balcão" pode ser entendida como um empreendimento de pequeno vulto, que emprega menos de 100 pessoas e costumam ser conduzidos com rédea curta pelos respectivos donos, os quais já conquistaram uma significativa representação no cenário comercial e industrial do país (Adriana Carvalho, 2002).

\section{2 - Restaurantes Naturais.}

São diversas as motivações e princípios filosóficos que personalizam a forma de vida e de alimentação do indivíduo que busca no alimento o equilíbrio nutricional e energético. A identificação do homem com o alimento e a bebida é fundamental. 
Principalmente no mundo contemporâneo, os restaurantes naturais se apresentam como alternativa à boa alimentação e se caracterizam pelo tipo de dieta oferecida. Em geral essas dietas visam o equilibrio energético. Entre elas podemos citar:

- A Macrobiótica que utiliza bastante cereais integrais;

- A dieta vegetariana se baseia no consumo de produtos de origem vegetal, crus e/ou cozidos.

- A Cridívora utiliza apenas vegetais crus. Os alimentos crus são mais bem aproveitados quando comidos frescos e logo após serem cortados.

- A Frugívora é integralmente baseada em frutas frescas.

- A ovo-lacto-vegetariana é rica em ovos, leite e derivados, vegetais e cereais integrais.

Hortaliças $^{2}$ e cereais são preconizados como alimentos essenciais aos que buscam no alimento a qualidade de sua saúde e de sua vida, por serem fontes de vitaminas, minerais e especialmente de fibras alimentares, importantes na ação de deglutição, na motilidade (movimentação) gástrica e, quando ingeridas no início das refeições, transmitem a sensação de saciedade, fazendo com que se coma menor quantidade de alimentos..

Estudos científicos comprovam que dietas baseadas em vegetais podem reduzir o risco de doenças crônicas, particularmente o câncer. O risco desta enfermidade em pessoas que consomem dietas ricas em frutas e vegetais é $50 \%$ menor em relação ao risco de pessoas que ingerem pouco desses alimentos. Alguns produtos de origem animal como peixe e óleos de peixe, também apresentam componentes com funções importantes na melhoria da saúde (Veja, Edição Especial -Saúde,novembro, 2002).

A adesão à comida natural está se tornando um hábito, há, inclusive, oferta de cursos que orientam e estimulam o consumo dos produtos alimentícios que caracterizam esta alimentação, valorizando a saúde e visando o auto-conhecimento e fortalecimento físico, mental, emocional e espiritual. A tabela 6, a seguir, apresenta o conteúdo de fibras alimentares em alguns vegetais, segundo Duarte Varo, 2002.

\footnotetext{
${ }^{2}$ Verduras, legumes, frutas são produtos classificados como hortaliças.
} 
TABELA 6 - Conteúdo de fibras alimentares em alguns produtos de origem vegetal ( Duarte, Varo - Nutrição e Obesidade)

\begin{tabular}{|l|c|l|c|l|c|}
\hline Verduras e legumes & \%/ fibras alimentar & \multicolumn{1}{|c|}{ Frutas } & \%/fibras alimentar & Cereais & \%/fibras alimentar \\
\hline Alcachofra & 2,2 & Ameixa8 & 1,8 & Farelo de cereais & 10,6 \\
\hline Abóbora & 1,0 & Amora & 0,9 & Cereais & 10,6 \\
\hline Beterraba & 1,0 & Caqui & 1,9 & Aveia integral & 9,0 \\
\hline Brócolis & 4,1 & Figo cru & 1,6 & Arroz integral & 5,5 \\
\hline Beringela & 1,5 & Goiaba & 5,3 & Pão branco francês & 2,7 \\
\hline Couve & 3,1 & Morango & 2,1 & Pão preto de centeio & 10,8 \\
\hline Couve-flor & 1,8 & Pera & 22,4 & Pão de milho & 3,4 \\
\hline Cebola & 2,1 & Manga & 0,8 & Amendoim & 2,9 \\
\hline Ervilha & 7,8 & Banana & 1,8 & Amêndoas & 3,0 \\
\hline Feijão (qualquer tipo) & 7,75 & Laranja & 1,1 & Castanhas-do-Pará & \\
\hline Lentilha & 3,2 & Pêssego & 3,8 & Pastanha de caju & 0,6 \\
\hline Cenoura & 3,7 & Côco & 3,4 & Pipoca & 18,0 \\
\hline Milho-verde & 4,7 & Kiwi & & Azeitona & 15,5 \\
\hline Nabo (raiz e folha) & 2,2 & & & Granola & 2,6 \\
\hline Pimentão & 2,6 & & & Milho em grão & 10,5 \\
\hline Rabanete & 2,2 & & & 11,00 \\
\hline Salsa & 1,3 & & & \\
\hline
\end{tabular}




\section{Capítulo 2}

"Não conheço nada tão potente para destruir a saúde quanto uma alimentação equivocada".

Sir Robert McCarrison MD.

\section{PROCEDIMENTOS OPERACIONAIS EM EMPREENDIMENTOS GASTRONÔMICOS}

Unidades de produção de refeições se caracterizam por transformar produtos de origem animal e de origem vegetal em produtos semiprocessados ou produtos prontos para consumo. Produtos que se destinam a coletividades sadias ou a coletividades enfermas. Seu padrão legal de qualidade é a portaria nº 1 da Divisão Nacional de Vigilância Sanitária de Alimentos (Brasil, 1987).

A qualidade de um produto alimentício pode ser adequada, aparentemente adequada ou imprópria. Produto com adequada qualidade atende às especificações legais, nos aspectos físicos, químicos, sensoriais, higiênico-sanitários e nutricionais. A escolha, a conservação das matérias-primas e dos ingredientes, as técnicas de processamento e principalmente as condições de higiene na produção são fundamentais à obtenção de produtos com estas características (Araújo, 2000).

Produtos aparentemente adequados não apresentam características sensoriais (aroma, sabor, aparência) alteradas. Entretanto, podem estar comprometidos sob o aspecto higiênicosanitário. Alguns dos microrganismos presentes são perigosos. Não estragam os alimentos, mas levam consumidores a mal-estares, indisposições e doenças, podendo inclusive causar mortes. 
Produto impróprio tem aparência, aroma e sabor que indicam sua inadequação ao consumo. Falhas na seleção de produtos, nas operações de pré-preparo, preparo, cozimento/processamento, no tempo de espera e nas condições de higiene da produção são responsáveis por tais alterações. Geralmente, os microrganismos não são patogênicos (Araújo, 2000).

Estudos de caráter epidemiológico mostram que muitas das doenças causadas por alimentos produzidos em larga escala, são particularmente perigosas, devido, especialmente, às condições incorretas de armazenamento de insumos e de manipulação.

Para minimizar este problema, o Codex Alimentarius (organismo internacional que normatiza e padroniza alimentos) estabeleceu requisitos de higiene para o preparo de alimentos crus e para a manipulação de produtos cozidos e pré-cozidos. Estabeleceu normas para projetos, instalação e manutenção de unidades de produção, bem como requisitos de saúde e de higiene para funcionários; e técnicas de produção (Wilma Araújo, 2000).

A segurança alimentar pode ser entendida e definida como a capacidade de acesso de todas as pessoas, em qualquer momento, a alimentos nutricionalmente adequados e seguros e em quantidade suficiente (quantidade, qualidade e variedade) para levar uma vida ativa e saudável.

Constitui também segurança alimentar a aquisição de alimentos de boa qualidade, livre de contaminantes de natureza química, biológica, física ou de qualquer outra substância prejudicial à saúde. Para garantir segurança alimentar é indispensável monitorar todas as etapas operacionais, quais sejam: recepção, armazenamento, pré-preparo, preparação, cocção, refrigeração, congelamento, descongelamento, reaquecimento, porcionamento, distribuição e transporte (Luciane Cardoso; Lucilene Bentes e Wilma M.C.Araújo, 2003).

Acrescente-se que os empreendimento que oferecem refeições preparadas, tem responsabilidade civil e social e devem garantir e respeitar os direitos do consumidor, oferecendo segurança alimentar. Esse é um direito garantido pelo Código de Defesa do 
Consumidor, o qual estabelece em seu, artigo 6, Capítulo III, “... a proteção à vida, saúde e segurança contra riscos provocados por prática no fornecimento de produtos e serviços considerados perigosos ou nocivos". O mesmo instrumento legal define a responsabilidade perante a segurança dos produtos disponibilizados ao consumidor no seu artigo $12^{\circ}$, seção II, do Capítulo IV: “ o fabricante, o produtor, o construtor, nacional ou estrangeiro, e o importador respondem, independetemente da existência de culpa, pela reparação dos danos causados aos consumidores por defeitos decorrentes de projeto, fabricação, construção, montagem, fórmulas, manipulação, apresentação ou acondicionamento de seus produtos, bem como por informações insuficientes ou inadequadas sobre sua utilização e riscos".

Apesar das diferenças filosóficas, a produção e o consumo de alimentos em restaurantes do tipo natural compreendem principalmente a utilização de produtos de origem vegetal e alguns produtos de origem animal - aves e pescados, que requerem cuidados na manipulação para não perderem suas qualidades. As cozinhas, independentemente do tipo de restaurante, requerem estruturas fixas e móveis adequadas.

Alimentos e bebidas apresentam uma vida-útil caracterizada, sob determinada condição de estocagem, por uma condição inaceitável ou imprópria para consumo. Esta inaceitabilidade do produto pode estar relacionada com diversos aspectos: presença de microorganismos patogênicos e/ou deteriorantes, alterações na aparência, cor, odor, sabor e textura do alimento, perda de valor nutricional entre outros. Baseando-se neste grau de suscetibilidade, agrupam-se os alimentos em 2 categorias: perecíveis e semiperecíveis (Araújo, W.M.C ; Botelho, R.A.C. e Peretti, A. P. Araújo, H.M.C \& Matos, R. A. C. , 2002).

Pelo decreto estadual no 12.486 (São Paulo, 1978), perecíveis são alimentos in natura, produtos semipreparados ou produtos preparados para o consumo. Por sua natureza ou composição, necessitam de condições especiais de temperatura para conservação. Têm vidade-prateleira de 5 a 7 dias, se armazenados a temperaturas entre $4^{\circ} \mathrm{C}$ e $6^{\circ} \mathrm{C}$. Semiperecíveis são os que apresentam menor sensibilidade à deterioração de origem microbiológica. São 
alimentos submetidos a processamentos como cura, defumação e tratamento térmico (carnes curadas, defumadas, salgadas, queijos curados e outros).

O Codex Alimentarius (organismo internacional que regulamenta normas e padrões alimentares), a Sociedade Brasileira de Ciência e Tecnologia de Alimentos (1991 e 1992) e a OMS (2001) republicaram padrões sobre requisitos de higiene para cozer alimentos crus, manipular cozidos e pré-cozidos, afora normas para projetos, instalação e manutenção de unidades de produção e requisitos de saúde e de higiene para funcionários e técnicas de produção (procedimentos operacionais, 2003).

Fundamentado nessas publicações, visando aperfeiçoar as condições higiênico-sanitárias no preparo de alimentos e adequar a ação da Vigilância Sanitária, o Ministério da Saúde publicou a portaria n. ${ }^{0} 1.428$ (Brasil, 1993) com o propóstio de garantir a segurança/inoucidade dos alimentos, estabelecendo normas para a produção de alimentos.

Esta pesquisa foi de natureza exploratório-descritiva e teve como objetivo verificar o panorama de higiene de restaurantes do tipo natural localizados em Brasília/DF. Foram visitadas 8 restaurantes, perfazendo um percentual de aproximadamente $40 \%$ dos empreendimentos desse setor, localizadas no Plano Piloto, escolhidos de acordo com a disponibilidade dos proprietários.

O instrumento utilizado na coleta dos dados, foi o questionário apresentado no apêndice 1. Para avaliar a adequação dos restaurantes quanto à segurança alimentar, foi utilizada a Lista de Verificação das Boas Práticas de Fabricação em Estabelecimentos da Área de Alimentos da Agência Nacional de Vigilância sanitária (ANVISA, 2002). Assinalava-se sim (S) para os itens atendidos, não (N) para os itens não atendidos e não aplicável (NA) para itens não aplicáveis. Foram avaliados:

- Bloco 1 : Edificação e Instalações

- Bloco 2 : Equipamentos, móveis e utensílios

- Bloco 3 : Manipuladores 
- Bloco 4 : Fluxo de Produção (Produção e Transporte do Aimeertod)

- Bloco 5 : Programa de Controle de Qualidade (Documentação). 


\title{
Capítulo 3
}

\begin{abstract}
"O médico do futuro não prescreverá remédios, mas estimulará o interesse dos pacientes pelos cuidados do caráter humano, pela dieta alimentar e pelas causas e prevenção das doenças".
\end{abstract}

Thomas Alva Edison

\section{PANORAMA DE RESTAURANTES DO TIPO NATURAL EM BRASÍLIA/DF}

\subsection{Panorama dos Empreendimentos Gastronômicos}

O panoramal dos empreendimentos gastronômicos visitados foi verificado partir da aplicação de um questionário (anexo 1). Quanto ao nível de instrução, observa-se que a maioria dos proprietários é de nível superior. Verifica-se que dos 8 locais visitados, 4 oferecem os serviços para almoço e jantar (apenas sopas), 3 oferecem somente serviço no horário de almoço e ainda 1 que se diferencia oferecendo serviço diário de almoço de segunda feira a domingo e, uma vez por semana, oferece sopas em ambiente aconchegante e romantico, à luz de velas com apresentação de dança.

Em todos eles o horário de funcionamento para o serviço de almoço é semelhante, oscila entre $11 \mathrm{~h}$ e $15 \mathrm{~h}$, enquanto o horário para o jantar oscila entre $17 \mathrm{~h}$ e $20 \mathrm{~h}$. Apenas um, aquele que abre para jantar somente uma vez por semana, funciona das $19 \mathrm{~h}$ às $24 \mathrm{~h}$. 
De um modo geral a administração é exercida pelo proprietário ou por um deles quando em sociedade, ressalte-se que 4 desses empreendimentos tem estrutura familiar. Do universo pesquisado, 50\% (cinquenta por cento) foi montado pelos atuais proprietários e o restante adquirido de terceiros. Todos têm um responsável técnico pela produção, que normalmente é o proprietário e faz a supervisão de todas as tarefas.

Em apenas um essa função é exercida por um gerente, que por sua vez é supervisionado pelo proprietário.

Cozinheiro, auxiliar de cozinha, atendente, suqueiro, responsável fixo pela preparação e reposição da salada, caixa e faxineiro compôe o quadro de pessoal de cada empresa. Capacitação e reciclagem do pessoal são pontos cruciais. Apenas dois estabelecimentos oferecem, e assim mesmo de forma esporádica, oportunidade de participação em palestras ou qualquer outro tipo de treinamento relacionado com a área de produção. Orientação, vigilância, conversas isoladas sobre falhas cometidas, são algumas alternativas que funcionam como uma espécie de treinamento em serviço.

Os clientes, alvo de toda movimentação na cozinha e fora dela, parecem formar uma grande família. Cada restaurante tem seu grupo, que se mantém fiel, constituido por pessoas que adotaram aquele espaço como a própria casa. Solicitam pratos para o dia seguinte, sugerem novas inclusões no cardápio baseadas no próprio gosto, sendo atendidos de bom grado pelos proprietários. Esporádica aparece a clientela eventual, e ainda os que sempre chegam, aumentam e enriquecem o elenco de visitantes. Há ainda, aqueles que marcam presença duas vezes por semana, ou que frequentam durante algum tempo, desaparecem, mas um dia voltam.

Os clientes podem ser classificados como de bom nível sócio-econômico; a maioria pertence à classe média ou à classe alta. Nota-se, na opinião de todos os pesquisados, que a opção pela comida natural está relacionada com a questão de preservação da sáude. A convicção de tempos passados ligada à religiosidade ou de ordem filosófica esta abrindo 
espaço para a conscientização da necessidade de investir na saúde e na qualidade de vida. A tendência predominante é a naturalista, sem radicalismos.

O cardápio oferecido por esses restaurantes, é variado mas guarda uma certa semelhança, tanto na forma de preparar como de apresentar os pratos. A salada se faz presente, de forma abundante, no buffet dos serviços visitados. Entre os pratos salgados de maior aceitação destacam-se: o acarajé de soja, bobó de glutém, feijoada vegetariana, tofu grelhado, cebola caramelada, suflê de milho, torta de mandioca, torta de ricota, quibe de tofu. Das gulosemas doces, a torta de banana prevalece, é mais vendida em todos os restaurantes. Dos restaurantes visitados, surpreendentemente, 3 oferecem carne branca, de ave ou de pescados. De maneira geral a definição do cardápio é feita diariamente pelo proprietário com a assistência do pessoal da cozinha, excentuam-se apenas dois restaurantes cuja previsão é semanal, com eventuais alterações.

A aquisição de material também não difere muito entre as empresas pesquisadas. Todas tem fornecedores fixos e eventuais, que fazem entrega local mediante pedido por telefone. Recorrem, muitas vezes, aos supermercados e mercearias mais próximos para compras rápidas, consideradas imprevistas. As hortaliças são entregues diáriamente, na maioria produtos orgânicos, ou a cada dois dias, os proprietários se queixam da dificuldade de encontrar alguns produtos orgânicos no mercado local. Os produtos secos são estocados para uma semana ou 15 dias, dependendo da natureza do produto. Pesa nesse aspecto o problema de espaço, muito reduzido na maioria deles, traduzindo-se em condições precárias e fora do padrões legais estabelecidos.

O total de refeições servidas no almoço oscila entre 100 e 250 e no jantar entre 20 e 50.

O tempo de preparo das refeições não difere muito entre os locais visitados. Segundo dados obtidos nas entrevistas, os proprietários nescessitam de 4 horas para execução dessa tarefa. Apenas 2 preparam alguma coisa antecipadamente (12h a 24h), como, sobremesas, por exemplo. 
3.2. - Perfil higiênico-sanitário dos empreendimentos gastronômicos

\subsection{1 - SITUAÇÃO E CONDIÇÕES DA EDIFICAÇÃO E INSTALAÇÃO:}

Os restaurantes visitados foram identificados como A,B, C, D, E, F, G e H.

A Tabela 7 mostra o atendimento ou não dos restaurantes à ANVISA quanto ao item "Edificações e Instalações". Verifica-se que nas 8 empresas o atendimento às normas variou entre 20 e 44 itens de um total de 76 itens; os itens de não atendimento variaram entre 8 e 40 ; e aqueles não aplicáveis variaram entre 13 e 45.

TABELA 7

Edificação e Instalações

\begin{tabular}{|c|c|c|c|}
\hline Restaurantes & SIM & NÃO & NA \\
\hline A & 20 & 36 & 20 \\
\hline B & 25 & 11 & 40 \\
\hline C & 29 & 8 & 39 \\
\hline D & 27 & 24 & 25 \\
\hline E & 23 & 40 & 13 \\
\hline F & 23 & 8 & 45 \\
\hline G & 36 & 11 & 29 \\
\hline H & 44 & 10 & 22 \\
\hline
\end{tabular}

Com relação a deficiência no atendimento às normas vigentes, os principais problemas estão relacionados com a inadequação e higiene das instalações sanitárias para 
manipuladores de alimentos e com a ventilação e climatização do ambiente de produção de alimentos.

A renovação constante do ar é importante em cozinhas porque durante o processo de cocção das preparações ocorre exalação constante de vapores, o que torna o ar prejudicialmente carregado, afetando o conforto físico e emocional dos manipuladores.

Todos os restaurantes visitados estão instalados em lojas, localizadas no comércio das entre-quadras residenciais, adaptadas para essa finalidade. Em 4 deles a cozinha funciona no subsolo, com ventilação restrita. Registre-se como ponto crítico a questão das janelas, que são praticamente inexistentes, principalmente pela localização em subsolo e consequente falta de proteção contra insetos e roedores - telas milimétricas ou outro sistema.

Com referência à iluminação, encontrou-se níveis inadequados em quase todas as cozinhas visitadas.

A ambiência do trabalho tem peso considerável na produção de alimentos e, segundo Eneo Alves da Silva Jr., 1966, forma o "conjunto de elementos envolventes que condicionam as atividades administrativas operacionais e determinam, em grande parte, a qualidade e quantidade de trabalho produzido."

É importante ressaltar que o trabalho realizado em condições desfavoráveis, com equipamentos inadequados, ruídos excessivos, calor, umidade e iluminação insuficiente, causa desgaste humano expondo o trabalhador a doenças profissionais (Miranda,1998).

A busca de condições seguras e saudáveis no ambiente de trabalho significa proteger e preservar a vida e, principalmente, é mais uma forma de se construir qualidade de vida (Fundacentro, 2001).

Quanto a higienização do ambiente, na maioria dos restaurantes visitados, os produtos não são identificados e nem guardados em locais apropriados. O controle de diluição desses 
produtos é falho, principalmente pela falta de empregado capacitado para tal finalidade. A limpeza do ambiente contribui direta ou indiretamente para o nível de contaminação do alimento. Para completa destruição dos microrganismos, incluindo os patógenos, maior rigor deve ser dispensado principalmente para aqueles alimentos que são ingeridos sem passar pelo processo de cocção.

A exemplo de outros países, a legislação brasileira exige que todos os estabelecimentos que tem como proposta a produção de alimentos adotem as Boas práticas de Fabricação BPF, e em seguida, implantem a Análise de Perigos e Pontos Críticos de Controle - APPCC Ou HACCP ${ }^{3}$. Essa prática sem dúvida constitue modernos conceitos de gestão e controle de qualidade.

As Boas Práticas de Fabricação tem por finalidade alcançar um determinado padrão de identidade e qualidade de um produto e/ou serviço na área de alimentos incluindo-se bebidas, utensílios e materiais em contato com alimentos (Brasil, 1993). Essa norma estabelece os cuidados necessários no projeto e no uso de equipamentos, área física e instalações bem como mudança nos métodos de produção e no comportamento das pessoas envolvidas em todas as etapas de fabricação e distribuição de alimentos.

Integram também as BPF os Procedimentos Operacionais Padronizados. Como o nome mesmo indica constituem procedimentos formais que estabelecem instruções seqüênciais para a realização de operações na produção, armazenamento e transporte de alimentos.

\footnotetext{
${ }^{3}$ HACCP: nomenclatura oficial segundo o Codex Alimentarius.
} 
3.2.2 - Equipamentos, Móveis e Utensílios.

TABELA 8

Equipamentos, Móveis e Utensílios

\begin{tabular}{|c|c|c|c|}
\hline Restaurantes & SIM & NÃO & NA \\
\hline A & 8 & 11 & 2 \\
\hline B & 11 & 9 & 1 \\
\hline C & 12 & 5 & 4 \\
\hline D & 15 & 5 & 1 \\
\hline E & 8 & 11 & 2 \\
\hline F & 9 & 6 & 6 \\
\hline G & 16 & 4 & 1 \\
\hline H & 12 & 4 & 5 \\
\hline
\end{tabular}

A tabela 8 apresenta o perfil de adequação dos estabelecimentos à legislação, quanto ao item Equipamentos, Móveis e Utensílios.

Observe-se que dos 21 itens listados, a adequação à portaria n. ${ }^{\circ} 326$, de 30 de julho de 1997, publicada no DOU de 01 de agosto de 1997, oscilou entre 8 e 16 respostas. Por outro lado, o número de itens que indicam inadequação, variou entre 4 e 11 . Quanto aos itens não aplicáveis a indicação foi de 1 e 6 respostas.

Os equipamentos da maioria dos restaurantes visitados não são industriais. Os refrigeradores e freesers, relativamente conservados, são de uso doméstico e, de certa forma, atendem bem o volume de refeições diárias produzidas. O ponto fraco nesse aspecto é a ausência de termômetro e de registro sistemático de temperaturas.

Móveis de material inoxidável, resistentes à corrosão, de fácil desinfecção e de material não-contaminante, estão presentes em $80 \%$ das cozinha visitadas. 
Em dois restaurante foi notada a utilização de colheres de madeira. A alegação ou justificativa para tal prática é sempre a mesma, trata-se de material que não conduz calor, oferecendo em conseqüência maior conforto aos manipuladores. De acordo com a literatura oficial deve-se evitar o uso de equipamentos de madeira por se tratar de material bastante absorvente e de difícil higienização. Ressalte-se que equipamentos e utensílios quando inadequadamente higienizados transferem microorganismos de sua superfície aos alimentos por contaminação direta e/ou cruzada durante a manipulação e contariam disposições legais. (Lucianne Cardoso; Lucilene Bentes e Wilma M.C.Araújo, 2003).

Observou-se que 4 restaurantes não fazem o armazenamento dos utensílios de forma apropriada, ficam expostos ou pendurados em prateleira abertas. Esse procedimento contraria disposições legais que estabelecem que equipamentos, utensílios, recipientes usados na produção não podem constiuir risco à saúde (Brasil, 1997).

A Tabela 9, a seguir, evidencia a situação dos manipuladores de alimentos das cozinha visitadas quanto ao vestuário, hábitos higiênicos, estado de saúde, programa de saúde e capacitação. Com relação aos itens avaliados, observa-se que a adequação variou entre 5 e 10 itens, a não adequação entre 2 e 6 itens e os itens não aplicáveis tiveram variação entre 1 e 4. 
TABELA 9

Manipuladores

\begin{tabular}{|c|c|c|c|}
\hline Restaurantes & SIM & NÃO & NA \\
\hline A & 7 & 3 & 4 \\
\hline B & 5 & 6 & 3 \\
\hline C & 10 & 2 & 2 \\
\hline D & 9 & 4 & 1 \\
\hline E & 7 & 3 & 4 \\
\hline F & 6 & 4 & 4 \\
\hline G & 6 & 5 & 3 \\
\hline H & 7 & 5 & 2 \\
\hline
\end{tabular}

Em 6 restaurantes visitados verificou-se que os manipuladores de alimentos trabalham uniformizados, tem boa apresentação, asseio corporal, usam touca de proteção do cabelo e trabalham com satisfação. Em 2 restaurantes, a visita para entrevista ocorreu fora do horário de preparação da refeição, entretanto pelo aspecto de higiene da cozinha e informação do responsável pelo restaurante não é difícil concluir que há atendimento à legislação quanto a boa apresentação dos manipuladores.

Registre-se que dos 8 restaurantes entrevistados, 3 mantêm lavatório dentro da área de produção de alimentos e somente 2 colocaram cartaz de orientação sobre a correta lavagem das mãos, portanto, apresenta-se falho o controle de higienização das mãos antes da manipulação de alimentos, principalmente após qualquer interrupção.

De acordo com o texto "Procedimentos Técnicos na gestão de A\&B e a Responsabilidade Social (Lucianne Cardoso; Lucelene Bentes; Wilma .C.Araújo, 2003)", "Os manipuladores são os principais responsáveis pela contaminação dos alimentos. Devem ser treinados e conscientizados periodicamente sobre como praticar as medidas de higiene que 
protegem os alimentos de contaminações químicas, físicas e microbiológicas. Brincos relógios, pulseiras, anéis são fontes de contaminação. Acumulam resíduos, poeiras e abrigam microorganismos. São necessários cuidados específicos com luvas, toucas, máscaras. Destaque-se que parte da inobservância quanto aos hábitos higiênicos é conseqüência de fatores evidenciados na avaliação dos itens referentes às condições de edificação".

3.2.4 - Fluxo de Produção (Produção e Transporte do Alimento)

TABELA 10

Fluxo da Produção

(Produção e Tansporte do Alimento)

\begin{tabular}{|c|c|c|c|}
\hline Restaurantes & SIM & NÃO & NA \\
\hline A & & & 33 \\
\hline B & & & 33 \\
\hline C & & & 33 \\
\hline D & & & 33 \\
\hline E & & & 33 \\
\hline F & & & 33 \\
\hline G & & & 33 \\
\hline H & & & 33 \\
\hline
\end{tabular}

A pesquisa foi realizada junto a restaurantes do tipo natural, cujo processo de preparação e comercialização da refeição, ocorrem no mesmo dia. Consequentemente, os itens referentes ao transporte do alimento preparado não se aplicam ao trabalho ora desenvolvido. 
3.2.5 - Programa de Controle de Qualidade (Documentação)

TABELA 11

Documentação

\begin{tabular}{|c|c|c|c|}
\hline Restaurantes & SIM & NÃO & NA \\
\hline A & & 16 & 9 \\
\hline B & & 17 & 8 \\
\hline C & 1 & 16 & 8 \\
\hline D & 4 & 13 & 8 \\
\hline E & & 16 & 9 \\
\hline F & & 16 & 9 \\
\hline G & 1 & 16 & 8 \\
\hline H & 1 & 16 & 8 \\
\hline
\end{tabular}

A Tabela 11 mostra a baixa adequação aos dispositivos legais dos itens referentes a documentação. Poucos restaurantes do universo pesquisado, conhecem e utilizam o Manual de Boas Práticas de Fabricação. Apenas um restaurante elaborou algumas normas de funcionamento mas ainda não as colocou em prática. Na maioria dos restaurantes, alvos dessa pesquisa, não existe POP - Procedimentos Operacionais Padronizados, o funcionamento é baseado no empirismo e em muitos aspectos na improvização e até mesmo na criatividade dos dirigentes.

Os restaurantes visitados podem ser classificados como empresas de pequeno porte, portanto, considera-se que os equipamentos, móveis e utensílios neles existentes estão compatíveis com o volume de refeições produzidas. Os móveis em todos eles destacam-se pela simplicidade e boa qualidade. Os equipamentos, de maneira geral não são de porte industrial. A falha nesse aspecto é quanto ao controle diário de temperaturas, que não chega a ser prejudicial se considerada a natureza dos produtos armazenados e o reduzido tempo de armazenamento. Ressalte-se que apenas 3 restaurantes trabalham com carnes de aves e de pescados, alimentos que exigem maior rigor na questão de armazenamento. 


\section{Capítulo 4}

"Os temperos trazem uma ponta de malícia para os pratos; os aromas têm por objetivo reavivar lembranças".

(Hervê This)

\section{CONCLUSÕES E CONSIDERAÇÕES FINAIS}

A pesquisa, realizada em 8 restaurantes que servem comida do tipo natural, indica que o funcionamento, preparação e comercialização de refeições está dissociada da literatura oficial, resultando no descumprimento das normas estabelecidas no Manual de Boas Prática de Fabricação, aprovado pela portaria n. ${ }^{0} 326$, de 30 de julho de 1997, publicada no DOU de 01 de agosto de 1997.

O panorama higiênico-sanitário dessas empresas variou entre 27,94\% e 49,26\% de atendimento dos itens objeto da verificação, ficando, portanto, classificadas no grupo 3. É importante registrar que os itens referentes ao fluxo de produção (Produção e Transporte do Alimento) foram excluídos em virtude da não aplicação aos restaurantes, os quais produzem e comercialização o produto no mesmo dia e no mesmo local.

O Manual de Boas Práticas de Fabricação, do ponto de vista higiênico-sanitário, classifica os estabelecimentos produtores/industrializadores de alimentos em 3 grupos, mediante 
sistematização dos dados obtidos em cada item, qual seja: Grupo 1: de 76 a 100\% de atendimento dos itens; Grupo 2: de 51 a 75\% de atendimento dos itens; Grupo 3: de 0 a 50\% de atendimento dos itens.

Não obstante a falta de cuidado no cumprimento da lesgislação vigente, alguns pontos positivos, listados a seguir, foram observados e podem dar suporte ao atendimento satisfatório das expectativas dos consumidores de alimentação natural:

- A preparação dos alimentos é feita no mesmo dia do consumo. O serviço de preparo inicia-se com 4 horas de antecedência e termina praticamente no horário de início do atendimento aos clientes, evitando que os alimentos fiquem expostos à temperaturas que possam favorecer a proliferação de microorganismos. Apenas 2 restaurantes preparam sobremesas com antecedência (12h a $24 \mathrm{~h})$;

- Pouca utilização de carnes. Somente 3 restaurantes oferecem carnes brancas de aves ou de pescados. Nesses 3 restaurantes verificou-se que a quantidade estocada não é grande, o que de certa forma reduz o espaço de tempo entre a aquisição e o consumo do produto;

- A renovação do estoque de material seco é frequente. O maior período de estocagem verificado foi de 20 dias;

- As hortaliças são adquiridas diariamente ou a cada 2 dias, verificando-se que a maioria dos produtos são orgânicos, o que constitue forte fator de preservação da saúde, devido principalmente à ausência de substância químicas prejudiciais ao organismo.

- Na maioria dos restaurantes visitados o proprietário está sempre presente, fazendo a supervisão de todo trabalho, em especial do preparo das refeições, verificando, 
inclusive se a cocção está em padrão suficiente para eliminar evetual possibilidade de contaminação;

- O pessoal de cozinha, que manipula os alimentos, tem boa apresentação e trabalha uniformizado, inclusive com utilização de touca de proteção dos cabelos.

Os pontos acima citados podem reduzir o risco de contaminação dos alimentos e diminuir as probalidades de que micoorganismos patogênicos transmitidos pelos alimentos possam contaminar, sobreviver ou proliferar. Todavia não são suficientes para manter os padrões ideais de produção, ditados pelas normas legais.

As cozinhas são consideradas áreas de riscos e a razão para limpeza e sanitização é exatamente para prevenir a contaminação física, microbiológica e química. Além disso, as medidas de higiene imprimem maior durabilidade aos equipamentos; e contribuem para melhorar o desempenho dos manipuladores.

No processo de produção de refeições, cumprir as regras estabelecidas no Manual de Boas Práticas de Fabricação, significa respeitar os clientes, oferecendo serviços de qualidade e protegendo a integridade dos mesmos, bem como, das empresas fornecedoras de produtos.

Nesse sentido, é importante ressaltar que, nos dias atuais, o cliente apresenta um nível de exigência muito maior, está mais conscientizado de seus direitos, se sente mais amparado pelas leis, e, dificilmente aceitará realidades de tempos passadas.

Segundo publicação da Organização Mundial da Saúde (1997), mais de 60\% dos casos de doenças DVA's ${ }^{4}$ foram decorrentes de técnicas inadequadas de processamento e também por alimentos contaminados servidos em restaurantes.

\footnotetext{
${ }^{4}$ (doenças veiculadas por alimentos)
} 
O hábito de realizar refeições fora de casa está se tornando cada vez maior e uma das formas para atender essa demanda são os restaurantes self-service, os quais oferecem refeição variada, capaz de atender diferentes gostos e tem a vantagem do custo mais baixo, considerando que o preço está relacionado com o peso. O inconveniente, na maioria deles, é que o alimento preparado fica exposto nos balcões por longos períodos, muitas vezes sob temperaturas inadequadas, principalmente aqueles que devem ser mantidos em temperatura de refrigeração (até $10^{\circ} \mathrm{C}$ ) como saladas, colocando em dúvida o padrão de qualidade. (Cátia Regina Storck - Nutricionista pela UNIFRA; Milliane Andrea Marques Freire Dias - Nutricionista da UFRN, 2003)

Foi observado que nos estabelecimentos self service participantes da pesquisa, as preparações, tanto frias quanto quentes não estão de acordo com as recomendações vigentes na Portaria n¹428, de 26/11/93 (MS - Ministério da Saúde), a qual especifica que preparações frias devem se manter em até $10^{\circ} \mathrm{C}$ e preparações quentes, acima de $60^{\circ} \mathrm{C}$, sendo essas as condições adequadas para garantir a segurança do produto.

O binômio tempo $\mathrm{x}$ temperatura é um fator muito importante na distribuição de refeições. Ele deve ser monitorado diariamente, com o auxílio de termômetros, sendo que o responsável do restaurante deve estar consciente desta necessidade (Silva Junior, 2001).

O HACCP - Hazard Analysis Critical Control Point Sistem - é uma metodologia que está sendo muito utilizada atualmente para identificar, determinar e controlar os perigos durante 0 processo de produção de alimentos. Ela oferece uma abordagem racional para o controle dos perigos suscetíveis aos microorganismos (APPCC, 1997).

Outro ponto crítico levantado é quanto ao controle de pragas, que é realizado na maioria dos restaurantes visitados, porém de forma pouco criteriosa. Verificou-se que não é exigido do prestador desse serviço a relação de materiais utilizados nas desinsetizações, a fim de constatar se são adequados ao tipo de serviço de alimentação e se são aprovados pelo Ministério da saúde. 
Diante de tudo que foi observado, registrado e comentado, conclui-se que se faz necessária a implantação, nos restaurantes do tipo natural, do Manual de Boas Práticas de Fabricação (MBPF), ferramenta que contém informações importantes para que uma unidade de alimentação e nutrição atinja padrão ideal de identidade e qualidade de um produto e/ou serviço.

Esse manual contém informações sobre higiene pessoal, ambiental e de alimentos, manipulação durante as várias etapas da produção, desde a recepção até a distribuição e transporte, controle integrado de pragas, visitantes e condições estruturais (Silva Junior, 2001). 
5. BIBLIOGRAFIA

ARAÚJO, Wilma M.C. e outras, Texto 11 - Procedimentos técnicos na gestão de A\&B e a responsabilidade social, Brasília: CBTUR, 2003. 6 p.

ARAÚJO, Wilma M. C., Guia tecnológico para produzir refeições. Aprovado para publicação pela Editora da Universidade de Brasília (no Prelo), 2000.

ARAúJO, W.M.C.; Ginani, V.C.; Botelho, R.B.A.; Peretti, A. P.; Araújp, W. M. C. \& Matos, R. A. C., Qualidade e segurança alimentar na indústria da hospitalidade. Anais do I Congresso de Docência e Pesquisa em Turismo - Perspectivas na Formação do Pesquisador de Turismo. Campo Largo. Paraná (Doc. 9.4.41), 2002.

BRASIL, Agência Nacional de Vigilância Sanitária, Lista de verificação das Boas Práticas de Fabricação em Estabelecimentos da Área de Alimentos. Brasília (DF), 1997.

BRASIL, Portaria n. ${ }^{\circ} 326$ de 30 de julho de 1997. Aprova regulamento técnico: "Condições higiênico-sanitárias e Boas Práticas de Fabricação para estabelecimentos produtores/ industrializadores de alimentos". Diário Oficial da União, Brasília (DF), 01 de agosto de 1997. Seção I.

BRASÍLIA. Ministério da Saúde. Portaria n. ${ }^{\circ}$ 1428, 1993. Determina condutas e critérios na elaboração do Manual de Boas Práticas de Fabricação e determina e obriga a implantação das Boas Práticas de Fabricação em todos os estabelecimentos produtores e prestadores de serviços na Área de alimentação.

CARVALHO, Adriana; Ramiro, Denise. Porque eles venceram. Veja, São Paulo,03 abr.2002, Edição 1745, p.88. 
DAVIES, Carlos Alberto, Alimentos\&Bebidas, 2.ed., Caxias do Sul: EDUCS, 2001. 240 p.

LÔBO, Alexandre, Manual de estrutura e organização do restaurante comercial, São Paulo: Atheneu, 1999. 135 p.

MAZZOLI, Mentore, Restaurantes, Rio de Janeiro: Rio, 1978. 124 p.

MAZZOLI, Mentore, Administração em hotelaria e recepção, Rio de Janeiro: Rio, 1979. 142 p.

ORNELLAS, Lieselotti Hoeschi, A alimentação através dos tempos, Rio de Janeiro:FENAME, 1978. $288 \mathrm{p}$.

SILVA FILHO, Antônio Romão A. da, Manual básico para planejamento e projeto de restaurantes e cozinhas industriais, São Paulo: Varela, 1996. 232 p.

SILVA JR, E.A . da, Manual de controle higiênico-sanitário em alimentos, 2.ED., São Paulo: Varela, 2003. 385 p.

THIS, Hervé , Um cientista na cozinha, Nelson dos Reis, São Paulo: Ática, 1996. 240p.

http://www.nutricaoempauta.com.br/novo/50/foodservice.html, acessado em 6/11/2003. www.lincx.com.br/orientacao/alimentos dietas.html-18k , acessado em 6/11/2003-11-29. http://www.midavid.hpg.ig.com.br/bpf.htpl , acessado em 8/11/2003. http://www.legalizaregistros.com.br/script php/clipping.php?tipoclipp=06numclipp=24 acessado em 17/11/2003.

http://www.nutricaoempauta.com.br/novo/37/matcapa.html, acessado em 25/11/2003. http://www.nutricaoempauta.com.br/novo/57/nutriclinica.hatml, acessado em 25/11/2003. http://www.midavid.hpg.ig.com.br/bpf.html, acessado em 26/11/2003. 
ANEXO 1

LISTA DE VERIFICAÇÃO DAS BOAS PRÁTICAS DE FABRICAÇÃO EM ESTABELECIMENTOS PRODUTORES/INDUSTRIALIZADORES DE ALIMENTOS

\begin{tabular}{|c|c|c|c|}
\hline \multicolumn{4}{|c|}{ NÚMERO: $\quad$ /ANO } \\
\hline \multicolumn{4}{|c|}{ A - IDENTIFICAÇÃO DA EMPRESA: } \\
\hline \multicolumn{4}{|c|}{ 1 - RAZÃO SOCIAL: } \\
\hline \multicolumn{4}{|c|}{2 - NOME DE FANTASIA: } \\
\hline 3-ALVARÁ & A SANITÁRIA: & \multicolumn{2}{|c|}{4 - INSCRIÇÃO ESTADUAL/MNICIPAL? } \\
\hline $5-\mathrm{CNPJ} / \mathrm{CP}$ & & \multicolumn{2}{|c|}{ 6-TELEFONE: } \\
\hline $7-\mathrm{FAX}:$ & & \multicolumn{2}{|c|}{ 8-E-MAIL: } \\
\hline \multicolumn{2}{|c|}{ 9-ENDEREÇO: } & $10-\mathrm{N}$ & 11-COMPL.: \\
\hline 12-BAIRRO: & 13-MUNICÍPIO: & 14:UF: & 15-CEP \\
\hline \multicolumn{2}{|c|}{ 16-RAMO DE ATIVIDADE: } & \multicolumn{2}{|c|}{ 17-PRODUÇÃO MENSAL: } \\
\hline \multicolumn{2}{|c|}{ 18-NÚMERO DE FUNCIONÁRIOS: } & \multicolumn{2}{|c|}{ 19-NÚMERO DE TURNOS: } \\
\hline \multicolumn{2}{|c|}{ 20-CATEGORIA DE PRODUTOS: } & \multicolumn{2}{|c|}{ Descrição da Categoria: } \\
\hline \multicolumn{2}{|c|}{ Descrição da Categoria: } & \multicolumn{2}{|c|}{ Descrição da Categoria: } \\
\hline \multicolumn{2}{|c|}{ Descrição da Categoria: } & \multicolumn{2}{|c|}{ Descrição da Categoria: } \\
\hline \multicolumn{2}{|c|}{ 21-RESPONSÁVEL TÉCNICO: } & \multicolumn{2}{|c|}{ 22-FORMAÇÃO ACADÊMICA: } \\
\hline
\end{tabular}

\begin{tabular}{|c|c|c|c|}
\hline \multirow{2}{*}{\multicolumn{4}{|c|}{$\begin{array}{l}\text { B - AVALIAÇÃO } \\
\text { 1. EDIFICAÇÃO E INSTALAÇÕES }\end{array}$}} \\
\hline & & & \\
\hline 1.1 ÁREA EXTERNA: & & & \\
\hline $\begin{array}{l}\text { 1.1.1 Área externa livre de focos de insalubridade, de objetos em desuso ou estranhos ao } \\
\text { ambiente, de vetores e outros animais no pátio e vizinhança; de focos de poeira, de } \\
\text { acúmulo de lixo nas imediações, de água estagnada, dentre outros. }\end{array}$ & & & \\
\hline $\begin{array}{l}\text { 1.1.2 Vias de acesso interno com superficie dura ou pavimentada, adequada ao trânsito } \\
\text { sobre rodas, escoamento adequado e limpas }\end{array}$ & & & \\
\hline 1.2 ACESSO: & & & \\
\hline 1.2.1 Direto, não comum a outros usos (habitação). & & & \\
\hline 1.3 ÁREA INTERNA & & & \\
\hline 1.3.1 Área interna livre de objetos em desuso ou estranhos ao ambiente: & & & \\
\hline 1.4 PISO: & & & \\
\hline $\begin{array}{l}\text { 1.4.1Material que permite fácil e apropriada higienização (liso, resistente, drenado com } \\
\text { declive, impermeável e outros). }\end{array}$ & & & \\
\hline $\begin{array}{l}\text { 1.4.2 Em adequado estado de conservação (livre de defeitos, rachaduras, trincas, buracos e } \\
\text { outros). }\end{array}$ & & & \\
\hline $\begin{array}{l}\text { 1.4.3 Sistema de drenagem dimensionado adequadamente, sem acúmulo de residuos. } \\
\text { Drenos, ralos sinfonados e grelhas colocadaos em locais adequados de forma a facilitar o } \\
\text { escoamento e proteger contra a entrada de baratas, roedores etc. }\end{array}$ & & & \\
\hline 1.5 TETOS: & & & \\
\hline $\begin{array}{l}\text { 1.5.1 Acabamento liso, em cor clara, impermeável, de fácil limpeza e, quando for o caso, } \\
\text { desinfecção. }\end{array}$ & & & \\
\hline $\begin{array}{l}\text { 1.5.2 Em adequado estado de conservação (livre de trincas, rachaduras, umidade, bolor, } \\
\text { descascamentos e outros). }\end{array}$ & & & \\
\hline 1.6 PAREDES E DIVISÓRIAS: & & & \\
\hline 1.6.1 Acabamento liso, impermeável e de fácil higienização até uma altura adequada para & & & \\
\hline
\end{tabular}


todas as operações. De cor clara.

1.6.2 Em adequado estado de conservação (livres de falhas, rachaduras, umidade, descascamentos e outros).

1.6.3 Existência de ângulos abaulados entre as paredes e o piso e entre as paredes e o teto. 1.7- PORTAS:

1.7.1 Com superficie lisa, de fácil higienização, ajustadas aos batentes, sem falhas de revestimento.

1.7.2 Portas externas com fechamento automático (mola, sistema eletrônico ou outro) e com barreiras adequadas para impedir entrada de vetores e outros animais (telas milimétricas ou outro sistema).

1.7.3 Em adequado estado de conservação (livres de falhas, rachaduras, umidades, descascamento e outros).

1.8- JANELAS E OUTRAS ABERTURAS:

1.8.1 Em superficie lisa, de fácil higienização, ajustadas aos batentes, sem falhas de revestimento.

1.8.2 Existência de proteção contra insetos e roedores (telas milimétricas ou outro sistema). 1.8.3 Em adequado estado de conservação (livres de falhas, rachaduras, umidade, descascamento e outros).

1.9 ESCADAS, ELEVADORES DE SERVIÇO, MONTACARGAS E ESTRUTURAS AUXILIARES

1.9.1 Construídos, localizados e utilizados de forma a não serem fontes de contaminação.

1.9.2 De material apropriado, resistente, liso e impermeável, em adequado estado de conservação.

1.10- INSTALAÇÕES SANITÁRIAS E VESTUÁRIOS PARA OS MANIPULADORES:

1.10.1 Quando localizados isolados da área de produção, acesso realizado por passagens cobertas e calçadas.

1.10.2 Independente para cada sexo (conforme legislação específica), identificados e de uso exclusivo para manipuladores de alimentos.

1.10.3 Instalações sanitárias com vasos sanitários, mictórios e lavatórios íntegros e em proporção adequada ao número de empregados (conforme legislação específica).

1.10.4 Instalações sanitárias servidas de água corrente, dotadas preferencialmente de torneiras com acionamento automático e conectadaa à rede de esgoto ou fossa séptica.

1.10.5 Ausência de comunicação direta (incluíndo sistema de exaustão) com a área de trabalho e de refeições.

1.10.6 Portas com fechamento automático (mola, sistema eletrônico ou outro).

1.10.7 Pisos e paredes adequadas e apresentando satisfatório estado de conservação.

1.10.8 iluminação e ventilação adequadas.

1.10.9 Instalações sanitárias dotadas de produtos destinados à higiene pessoal: papel higiênico, sabonete líquido inodoro anti-séptico ou sabonete líquido inodoro e anti-séptico, toalhas de papel não reciclado para as mãos ou outro sistema higiênico e seguro para secagem.

1.10.10 Presença de lixeiras com tampas e com acionamento não manual

1.10.11 Coleta frequente de lixo.

1.10.12 Presença de aviso com os procedimentos para lavagem das mãos.

1.10.13 Vestiários com área compatível e armários individuais para todos os manipuladores

1.10.14 Duchas ou chuveiros em número suficiente (conforme legislação específica), com água fria ou com água quente e fria.

1.10.15 Apresentam-se organizados e em adequado estado de conservação.

1.11- INSTALAÇÕES SANITÁRIAS PARA VISITANTES E OUTROS:

1.11.1 Instaladas totalmente independente da área de produção ehigienizados.

1.12-LAVATÓRIOS NA ÁREA DE PRODUÇÃO:

1.12.1 Existência de lavatórios na área de manipulação com água corrente, dotados

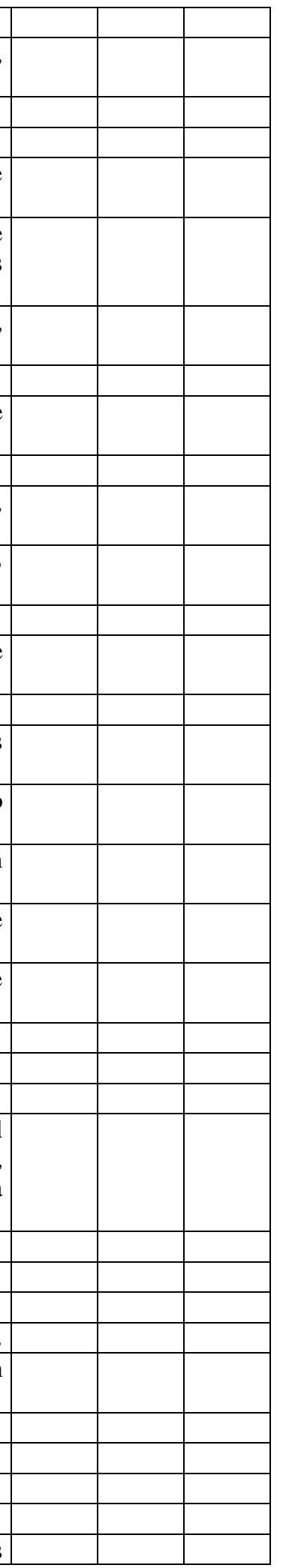


preferencialmente de torneira com acionamento automático, em posições adequadas em relação ao fluxo de produção e serviço e em número suficiente de modo a atender toda a área de produção.

1.12.2 Lavatórios em condições de higiene, dotados de sabonete líquido inodoro antiséptico, toalhas de papel não reciclado ou outro sistema higiêncio e seguro de secagem e coletor de papel acionado sem contato manual.

(2)

\begin{tabular}{|l|}
\hline B - AVALIAÇÃO: \\
\hline 1.13- ILUMINAÇÃO E INSTLAÇÕES ELÉTRICAS: \\
\hline 1.13 .1 Nathal OU aIticial adequà atividade desenvo
\end{tabular}

1.13.1 Natural ou artificial adequada à atividade desenvolvida, sem ofuscamento, reflexos fortes, sombras e contrastes excessivos.

1.13.2 Luminária com proteção adequada contra quebras e em adequado estado de conservação.

1.13.3 Instalações elétricas imbutidas ou quando exteriores revestidas por tubulações isolantes e presas a paredes e tetos.

1.14-VENTILAÇÃO E CLIMATIZAÇÃO:

1.14.1 Ventilação e circulação de ar capazes de garantir o conforto térmico e o ambiente livre de fungos, gases, fumaça, pós, particulas em suspensão e condensação de vapores sem causar danos à produção.

1.14.2 Ventilação artificial por meio de equipamento(s) higienizado(s) e com manutenção adequada ao tipo de equipamento.

1.14.3 Ambientes climatizados artificialmente com filtros adequados.

1.14.4 Existência de registro periódico dos procedimentos de limpeza e manutenção dos componentes do sistema de climatização (conforme legislação específica) afixado em local visível.

1.14.5 Sistema de exaustão e/ou insuflamento com troca de ar capaz de prevenir contaminações.

1.14.6 Sistema de exaustão e ou insuflamento dotados de filtros adequados.

1.14.7 Captação e direção da corrente de ar não seguem a direção da área contaminada para área limpa.

1.15-HIGIENIZAÇÃO DAS INSTALAÇÕES:

1.15.1 Existência de um responsável pela operação de igienização, comprovadamente capacitado.

1.15.2 Frequência de higienização das instalções adequada.

1.15.3 Existência de registro da higienização.

1.15.4 Produtos de higienização regularizado pelo Ministério da Saúde.

1.15.5 Disponibilidade dos produtos de higienização necessários à realização da operação.

1.15.6 A diluição dos produtos de higienização, tempo de contato e modo de uso/aplicação obedecem às instruções recomendadas pelo fabricante.

1.15.7 Produtos de higienização identificados e guardados em local adequado.

1.15.8 Disponibilidade e adequação dos utensílios (escovas, esponjas etc.) necessários à realização da operação. Em bom estado de conservação.

1.15.9 Higienização adequada

1.16-CONTROLE INTEGRADO DE VETORES E PRAGAS URBANAS:

1.16.1 Ausência de vetores e pragas urbanas e qualquer evidência de sua presença como fezes, ninhos e outros.

1.16.2 Adoção de medidas preventivas e corretivas com o objetivo de impedir a atração, o abrigo, o acesso e ou proliferação de vetores e pragas urbanas.

1.16.3 Em caso de adoção de controle químico, existência de comprovante de execução do serviço, expedido por empresa especializada.

1.17-ABASTECIMENTO DE ÁGUA:

1.17.1 Sistema de abasteciemento ligado à rede pública.

\begin{tabular}{|llll} 
1.17.2 Sistema de captação própria, protegido, revestido e distante de fonte de &
\end{tabular}

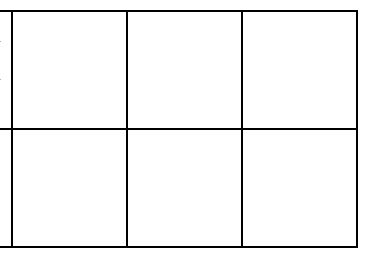


contaminação.

1.17.3 Reservatório de água acessível com instalação hidráulica com volume, pressão e temperatura adequados, dotado de tampas, em satisfatória condição de uso, livre de vazamentos, infiltrações e descascamentos.

1.17.7 Encanamento em estado satisfatório e ausência de infriltações e interconexões, evitando conexão cruzada entre água potável e não potável.

1.17.8 Existência de planilha de registro da troca periódica de elemento filtrante.

1.17.9 Potabilidade da água atestada por meio de laudoslaboratoriais, com adequada periodicidade, assinados por técnico responsável pela análise ou expedidos por empresa terceirizada.

1.17.10 Disponibilidade de reagente e equipamentos necessários à análise da potabilidade da água realizadas no estabelecimento.

1.17.11 Controle de potabilidade realizado por técnico comprovadamente capacitado.

1.17.12 Gelo produzido com água potável, fabricado, manipulado e estocado sob condições sanitárias satisfatórias, quando destinado a entrar em contato com alimento ou superficie que entre em contato com o alimento.

1.17.13 Vapor gerado a partir de água potável quando utilizado em contato com o alimento superficie que entre em contato com o alimento.

\begin{tabular}{|c|c|c|c|}
\hline B - AVALIAÇÃO & SIM & NÃO & $\mathrm{NA}(*)$ \\
\hline 1.18-MANEJO DOS RESIDUOS: & & & \\
\hline $\begin{array}{l}\text { 1.18.1 Recipientes para coleta de residuos no interior do estabelecimento, de fácil } \\
\text { higienização e transporte, devidamente identificados e higienizados constatemente; uso de } \\
\text { sacos de lixo apropriados. Quando necessário, recipientes tampados com acionamento não } \\
\text { manual. }\end{array}$ & & & \\
\hline $\begin{array}{l}\text { 1.18.2 Retirada freqüente dos residuos da área de processamento, evitando focos de } \\
\text { contaminação. }\end{array}$ & & & \\
\hline 1.18.3 Existência de área adequada para estocagem dos resinduos. & & & \\
\hline 1.19-ESGOTAMENTO SANITÁRIO: & & & \\
\hline $\begin{array}{l}\text { 1.19.1 Fossas, esgotos conectados à rede pública, caixas de gordura em adequado estado de } \\
\text { conservação e funcionamento. }\end{array}$ & & & \\
\hline 1.20-LEIAUTE: & & & \\
\hline $\begin{array}{l}\text { 1.20.1 Leiaute adequado ao processo produtivo: número, capacidade e distribuição das } \\
\text { dependências de acordo com o ramo de atividade, volume de produção e expedição. }\end{array}$ & & & \\
\hline $\begin{array}{l}\text { 1.10.2 Áreas para recepção e depósito de matéri-prima, ingredientes e embalagens distintas } \\
\text { das áreas de produção, armazenamento e expedição de produto final. }\end{array}$ & & & \\
\hline OBSERVAÇÕES & & & \\
\hline
\end{tabular}

\begin{tabular}{|c|c|c|c|}
\hline \multirow{2}{*}{\multicolumn{4}{|c|}{$\begin{array}{l}\text { B - AVALIAÇÃO } \\
\text { 2. EQUIPAMENTOS, MÓVEIS E UTENSÍLIOS }\end{array}$}} \\
\hline & & & \\
\hline 2.1 EQUIPAMENTOS & & & \\
\hline 2.1.1 Equipamentos da linha de produção com desenho e número adequado ao ramo. & & & \\
\hline 2.1.2 Dispostos de forma a permitir fácil acesso e higienização adequada. & & & \\
\hline $\begin{array}{l}\text { 2.1.3 Superficies em contato com alimentos lisas, íntegras, impermeáveis, resistentes à } \\
\text { corrosão, de fácil higienização e de material não contaminante. }\end{array}$ & & & \\
\hline 2.1.4 Em adequado estado de conservação e funcionamento. & & & \\
\hline $\begin{array}{l}\text { 2.1.5 Equipamentos de conservação dos alimentos (refrigeradores, congeladores, câmaras } \\
\text { frigoríficas e outros), bem como os destinados ao processamento térmico, com medidor de } \\
\text { temperatura localizado em local apropriado e em adequado funcionamento. }\end{array}$ & & & \\
\hline $\begin{array}{l}\text { 2.1.6 Existência de planilhas de registro de temperatura, conservadas durante período } \\
\text { adequado. }\end{array}$ & & & \\
\hline 2.1.7 Exixtência de registros que comprovem que os equipamentos e maquinários passam & & & \\
\hline
\end{tabular}

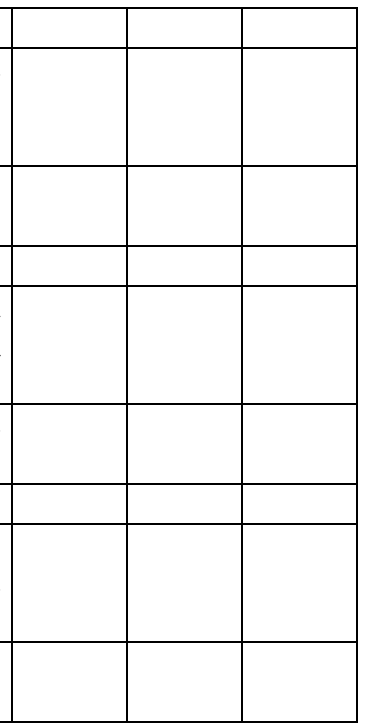




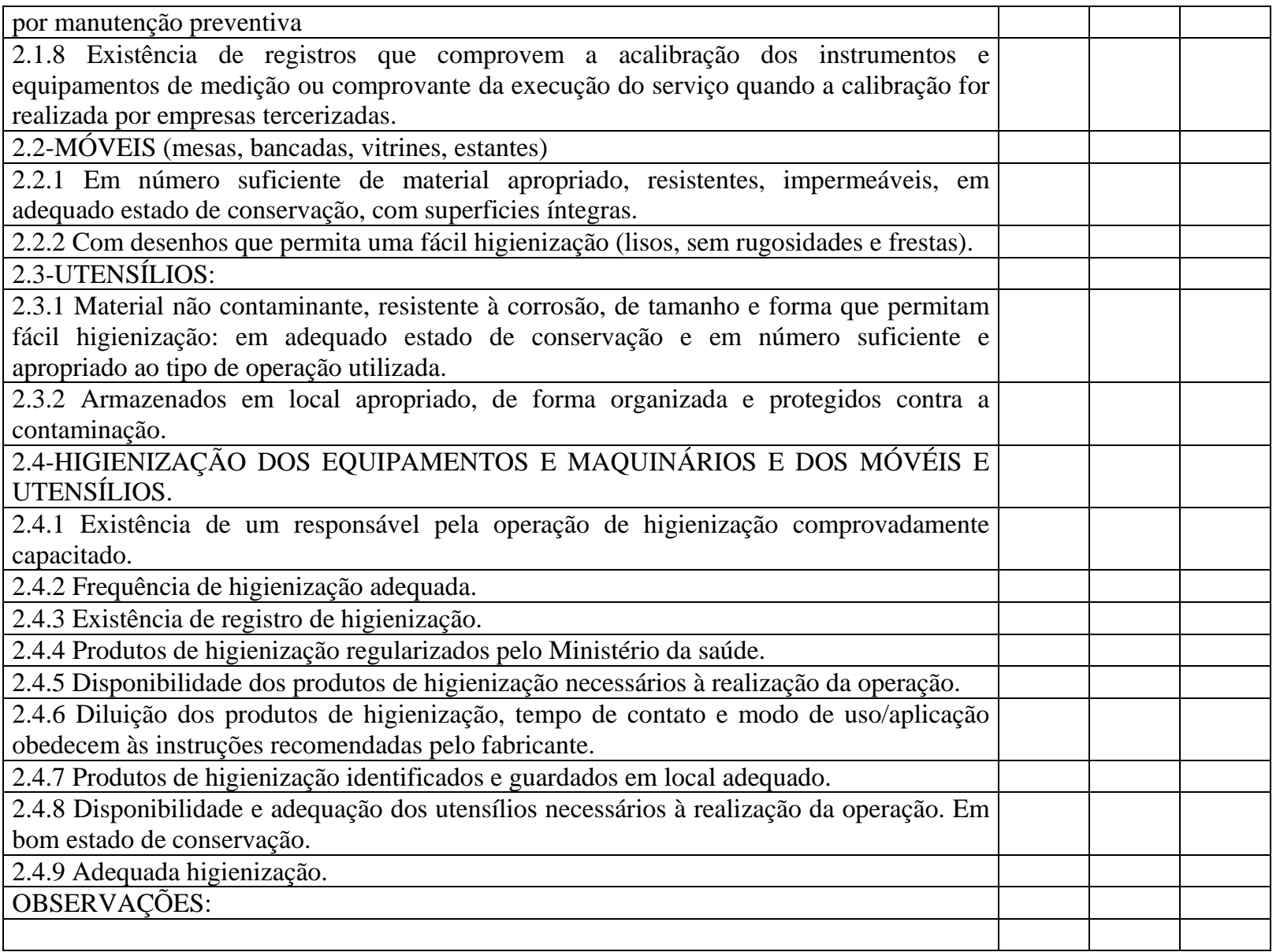

\begin{tabular}{|l|l|l|l|}
\hline B - AVALIAÇÃO & SIM & NÃO & NA(*) \\
\hline 3-MANIPULADORES & & & \\
\hline 3.1 VESTUÁRIO: & & \\
\hline $\begin{array}{l}\text { 3.1.1 Utilização de uniforme de trabalho de cor clara, adequado à atividade e exclusivo } \\
\text { para área de produção. }\end{array}$ & & & \\
\hline 3.1.2 Limpos e em adequado estado de conservação. & & \\
\hline $\begin{array}{l}\text { 3.1.3 Asseio pessoal: boa apresentação, asseio corporal, mãos limpas, unhas curtas, sem } \\
\text { esmalte, sem adornos (anéis, pulseiras, brincos, etc.), manipuladores barbeados, com os } \\
\text { cabelos protegidos). }\end{array}$ & & & \\
\hline 3.2-HABITOS HIGIÊNICOS: & & \\
\hline $\begin{array}{l}\text { 3.2.1 Lavagem cuidadosa das mãos antes da manipulação de alimentos, principalmente } \\
\text { após qualquer interrupção e depois do uso de sanitários. }\end{array}$ & & \\
\hline $\begin{array}{l}\text { 3.2.2 Manipuladores não espirram sobre os alimentos, não cospem, não tossem, não } \\
\text { fumam, não manipulam dinheiro ou não praticam outros atos que possam contaminar o } \\
\text { alimento. }\end{array}$ & & \\
\hline $\begin{array}{l}\text { 3.2.3 Cartazes de orientação aos manipuladores sobre a correta lavagem das mãos e demais } \\
\text { hábitos de higiene, afixados em locais apropriados. }\end{array}$ & & \\
\hline 3.3-ESTADO DE SAÚDE: & & & \\
\hline $\begin{array}{l}\text { 3.3.1 Ausência de afecções cutâneas, feridas e supurações; ausência de sintomas e } \\
\text { infecções respiratórias, gastrointestinais e oculares. }\end{array}$ & & \\
\hline 3.4-PROGRAMA DE CONTROLE DE SAÚDE: & & & \\
\hline
\end{tabular}




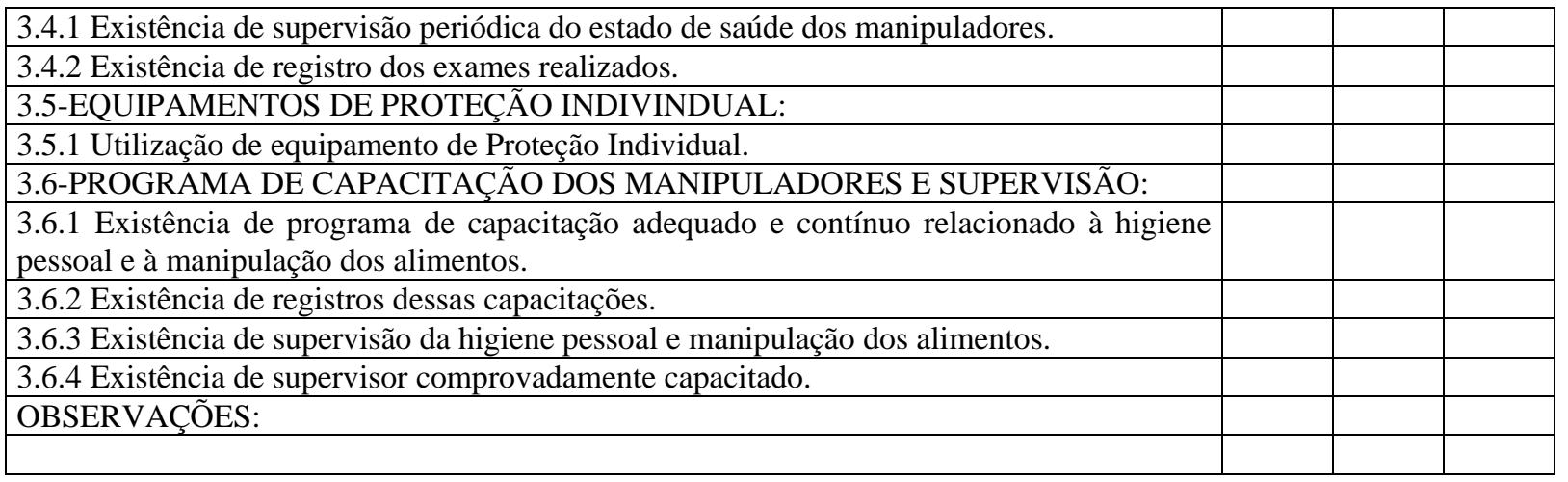

\begin{tabular}{|c|c|c|c|}
\hline B - AVALIAÇÃO & SIM & $\mathrm{NÃO}$ & $\mathrm{NA}(*)$ \\
\hline 4. PRODUÇÃO E TRANSPORTE DO ALIMENTO & & & \\
\hline 4.1 MATÉRIA-PRIMA, INGREDIENTES E EMBALAGENS: & & & \\
\hline $\begin{array}{l}\text { 4.1.1 Operações de recepção da matéria-prima, ingrediente e embalagens são realizadas em } \\
\text { local protegido e isolado da área de processamento. }\end{array}$ & & & \\
\hline 4.1.2 Materias-primas, ingredientes e embalagens inspecionados na recepção. & & & \\
\hline $\begin{array}{l}\text { 4.1.3 Existência de planilhas de controle na recepção (temperatura e caracteristicas } \\
\text { sensoriais, condições de transporte e outros). }\end{array}$ & & & \\
\hline $\begin{array}{l}\text { 4.1.4 Matéria-primas e ingredientes aguardando liberação e aqueles aprovados estão } \\
\text { devidamente identificados. }\end{array}$ & & & \\
\hline $\begin{array}{l}\text { 4.1.5 Matérias-primas, ingredientes e embalagens reprovados no controle efetuado na } \\
\text { recepção são devolvidos imediatamente ou identificados e armazenados em local separado. }\end{array}$ & & & \\
\hline 4.1.6 Rótulos da matéria-prima e ingredientes atendem à legislação. & & & \\
\hline $\begin{array}{l}\text { 4.1.7 Critérios estabelecidos para a seleção das matérias primas são baseados na segurança } \\
\text { do alimento. }\end{array}$ & & & \\
\hline $\begin{array}{l}\text { 4.1.8 Armazenamento em local adequado e organizado; sobre estrados distante do piso, ou } \\
\text { sobre paletes, bem conservados e limpos, ou sobre outro sistema aprovado, afastados das } \\
\text { paredes e distantes do teto de forma que permita apropriada higienização, iluminação e } \\
\text { circulação de ar. }\end{array}$ & & & \\
\hline $\begin{array}{l}\text { 4.1.9 Uso das matérias-primas, ingredientes e embalagens respeita a ordem de entrada dos } \\
\text { mesmos, sendo observado o prazo de validade. }\end{array}$ & & & \\
\hline 4.1.10 Acondicionamento adequado das embalagens a serem utilizadas. & & & \\
\hline $\begin{array}{l}\text { 4.1.11 Rede de frio adequada ao volume e aos diferentes tipos de matérias-primas e } \\
\text { ingredientes. }\end{array}$ & & & \\
\hline 4.2-FLUXO DE PRODUÇÃO: & & & \\
\hline $\begin{array}{l}\text { 4.2.1 Locais para pré-preparo (“áreas suja”) isolada da área de preparo por barreira física } \\
\text { ou técnica. }\end{array}$ & & & \\
\hline 4.2.2 Controle da circulação e acesso do pessoal. & & & \\
\hline 4.2.3 Conservação adequada de materiais destinados ao reprocessamento. & & & \\
\hline 4.2.4 Ordenado, linear e sem cruzamento. & & & \\
\hline
\end{tabular}

\begin{tabular}{|l|l|l|l|}
\hline B - AVALIAÇÃO & SIM & NÃO & NA(*) \\
\hline 4.3 ROTULAGEM E ARMAZENAGEM DO PRODUTO-FINAL & & & \\
\hline 4.3.1 Dizeres de rotulagem com identificação visível e de acordo com a legislação vigente. & & & \\
\hline 4.3.2 Produto final acondicionado em embalagens adequadas e íntegras. & & & \\
\hline $\begin{array}{l}\text { 4.3.3 Alimentos armazenados separados por tipo ou grupo, sobre estrados distantes do piso, } \\
\text { ou sobre paletes, bem conservados e limpos ou sobre outro sistema aprovado, afastado das } \\
\text { paredes e distantes do teto de forma a permitir apropriada higienização, iluminação e } \\
\text { circulação do ar. }\end{array}$ & & & \\
\hline \begin{tabular}{l} 
4.3.4 Ausência de material estranho, estragado ou tóxico. \\
\hline
\end{tabular} & & \\
\hline
\end{tabular}


4.3.5 Armazenamento em local limpo e conservado.

4.3.6 Controle adequado e existência de planilha de registro de temperatura, para ambientes com controle térmico.

4.3.7 Rede de frio adequado ao volume e aos diferentes tipos de alimentos.

4.3.8 Produtos avariados, com prazo de validade vencido, devolvidos ou recolhidos, do mercado devidamente identificados e armazenados em local separado e de forma organizada.

4.3.9 Produtos finais aguardando resultado analítico ou em quarentena e aqueles aprovados devidamente identificados.

4.4 CONTROLE DE QUALIDADE DO PRODUTO FINAL:

4.4.1 Existência de controle de qualidade do produto final.

4.4.2 Existência de programa de amostragem para análise laboratorial do produto final.

4.4.3 Existência de laudo laboratorial atestando o controle de qualidade do produto final, assinado pelo técnico da empresa responsável pela análise ou expedido por empresa tercerizada.

4.4.4 Existência de equipamentos e materiais necessários para análise do produto final realizadas no estabelecimento.

4.5-TRANSPORTE DO PRODUTO FINAL:

4.5.1 Produto transportado na temperatura especificada no rótulo.

4.5.2 Veículo limpo, com cobertura para proteção de carga. Ausência de vetores e pragas urbanas ou qualquer evidência de sua presença como fezes, ninhos e outros.

4.5.3 Transporte mantém a integridade do produto.

4.5.4 Veículo não transporta outras cargas que comprometam a segurança do produto.

4.5.5 Presença de equipamento para controle de temperatura quando se transporta alimentos que necessitam de condições especiais de conservação.

OBSERVAÇÕES

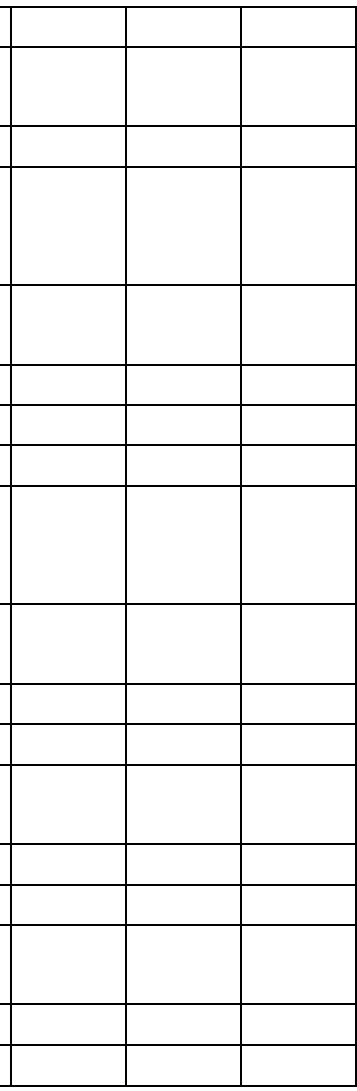

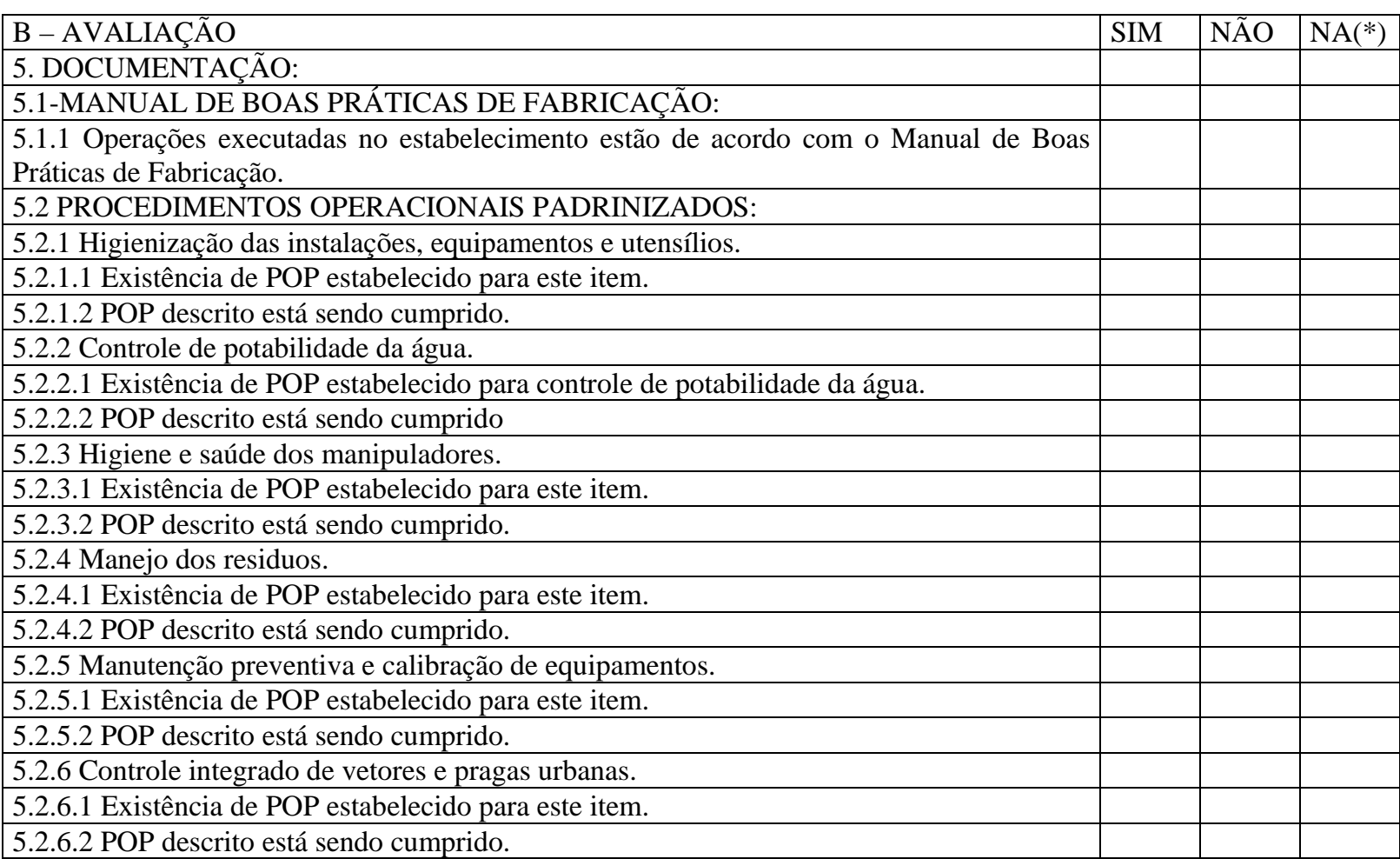


5.2.7 Seleção das matérias-primas, ingredientes e embalagens.

5.2.7.1 Existência de POP estabelecido para este item.

5.2.7.2 POP descrito está sendo cumprido.

\begin{tabular}{|l|l|l|l|}
\hline B - AVALIAÇÃO & SIM & NÃO & NA(*) \\
\hline 5.2.8 Programa de recolhimento de alimentos: & & & \\
\hline 5.2.8.1 Existência de POP estabelecido para este item. & & & \\
\hline 5.2.8.2 POP descrito está sendo cumprido. & & & \\
\hline OBSERVAÇÕES & & & \\
\hline & & & \\
\hline
\end{tabular}

\section{C - CONSIDERAÇÕES FINAIS}

\section{D - CLASSIFICAÇÃO DO ESTABELECIMENTO}

Compete aos órgãos de vigilância sanitária estaduais e distrital, em articulação com o órgão competente no âmbito federal, a construção do panorama sanitário dos estabelecimentos produtores/industrializadores de alimentos, mediante sistematização dos dados obtidos nesse item. O panorama sanitário será utilizado como critério para definição e priorização das estratégias institucionais de intervenção.

( ) GRUPI 1 - 76 100\% de atendimento dos itens; ( ) GRUPO 2 - 51 a 75\% de atendimento dos itens; ( ) GRUPO $3-0$ a $50 \%$ de atendimento dos itens.

\begin{tabular}{|l|l|}
\hline E - RESPONSÁVEIS PELA INSPEÇÃO & \\
\hline Nome e assinatura do responsável & Nome e assinatura do responsável \\
\hline Matrícula: & Matrícula: \\
\hline \multicolumn{2}{|c|}{} \\
\hline F - RESPONSÁVEL PELA EMPRESA & \\
\hline \multicolumn{2}{|c|}{ Nome e assinatura do responsável pelo estabelecimento } \\
\hline \multicolumn{2}{|c|}{} \\
\hline Local & Data \\
\hline
\end{tabular}

(*)NA: Não se aplica. 
APENDICE 1

UNIVERSIDADE DE BRASÍLIA - UNB

CENTRO DE EXCELÊNCIA EM TURISMO

POR FAVOR, RESPONDA O QUESTIONÁRIO ABAIXO. SUAS INFORMAÇÕES SERVIRÃO DE BASE PARA ELABORAÇÃO DE UMA MONOGRAFIA DE FINAL DO CURSO DE GESTÃO DE HOSPITALIDADE III.

1. RESTAURANTE: 2. TIPO DE SERVIÇO: Self-service

3. ENDEREÇO 4. Tel.

5. HORÁRIO DE FUNCIONAMENTO: a) Almoço b) Jantar:

6. PROPRIETÁRIO(A): $1^{\circ}() 2^{\circ}() 3^{\circ}()$ e-mail:

7. Qual o total de empregados do restaurante, por categoria?

\begin{tabular}{|c|c|c|c|c|c|c|c|}
\hline $\begin{array}{c}\text { Responsá- } \\
\text { vel Técnico }\end{array}$ & $\begin{array}{c}\text { Cozinhei- } \\
\text { ro(a) }\end{array}$ & $\begin{array}{c}\text { Aj.de } \\
\text { Cozinha }\end{array}$ & Atendente & Garçom & Atendente & Caixa & Outro \\
\hline & & & & & & & \\
\hline
\end{tabular}

7.1 - O pessoal recebe algum tipo de treinamento?

08. Como os ingrediente são adquiridos: 8.1 Fornecedor: fixo? ( ) 8.2 - Eventual ? ( ); 8.3 Especificar:

a) Supermercado ( ); b) Mercearia( ); c) Direto do produtor( ); d) Produção Própria: ( ); e) Outro

8.1 - São orgânicos ou não Orgânicos?

9. De que forma é feito o estoque? 9.1 - P/ uma semana; ( ) 9.2 - P/ quinze dias ( ); 9.3 - P/ um mês ( ).

10. Como avalia a qualidade dos alimentos?

11. Qual o número de refeições servidas diariamente? a) Almoço: $\quad$ b) Jantar

12. Qual o tempo de preparo das refeições?

13. Com que antecedência é iniciado o preparo das refeições?

14. Alguma coisa é preparada de véspera? 
15. Quais os produtos salgados de maior aceitação?

16. Quais os produtos doces de maior aceitação?

17. Quem define o cardápio e como essa decisão é tomada?

18. O cardápio é definido para quanto tempo? 18.1 - Um dia ( ); 18.2 - uma semana ( ); 18.3 - quinze dias ( ) 18.4 -um mês ( ).

19. O cardápio contempla algum tipo de carne branca? 19.1 - aves ( ); 19.2 - frutos do mar ( ); 19.3 Pescados ( );

20. Como pode ser classificada a clientela? 20.1 - homogênea ( ); 20.2 - Hetereogênea ( ); 20.3 Constante (fiel) ( ); $\quad 20.4-$ Eventual ( );

21 - Existe cliente fixo? 21.1 Quantos, aproximadamenre?

Se positivo faz entrega à domicílio para algum desses?

22. O restaurante promove alguma atividade (cultural, artística, social) que contribui para o entrosamento da clientela?

22.1 - Abre espaço para divulgações relacionadas com a área? Se positivo, de que forma?

23. Qual o nível sócio-econòmico predominante da clientela?

23.1 - Classe Média-baixa ( ）; 23.2 - classe-média-média ( ); 23.3 - classe média-alta ( ); 23.4 - outras:

24. Na sua visão e capacidade de observação, como pode ser definida a opção pela alimentação natural?

24.1 - Religiosidade ( ）; 24.2 - Saúde ( ）; 24.3-Modismo ( ）; 24.4 - Outras. Especificar:

25. Qual a tendência predominante da clientela? 25.1 - Vegetariana ( ); 25.2 - Naturalista ( );

25.3 - Macrobiótica ( ) ; 25.4 - Ovo lacto vegetal ( ); Outro

26. Além do fornecimento de refeições, o restaurante explora outra atividade como empório, fornecimento de buffet, etc.?

27. Algum procedimento está informatizado?

28. As instalações são próprias? 


\section{APÊNDICE 2}

PANORAMA DE RESTAURANTES DO TIPO NATURAL

TABULAÇÃO DOS DADOS COLETADOS

\begin{tabular}{|c|c|c|c|c|c|c|c|c|c|c|c|c|c|c|c|c|c|c|c|c|c|c|c|c|}
\hline \multirow{3}{*}{$\begin{array}{c}\text { ITENS DO MANUAL DE BOAS PRÁTICAS } \\
\text { DE FABRICAÇÃO }\end{array}$} & \multicolumn{24}{|c|}{ RESTAURANTES PESQUISADOS } \\
\hline & \multicolumn{4}{|c|}{ A } & \multicolumn{4}{|c|}{$\mathrm{B}$} & \multicolumn{4}{|c|}{$\mathrm{C}$} & \multicolumn{4}{|c|}{$\mathrm{D}$} & \multicolumn{4}{|c|}{$E$} & \multicolumn{4}{|c|}{$\mathrm{F}$} \\
\hline & Sim & Não & NA & Tot & Sim & Não & NA & Tot & Sim & Não & NA & Tot & Sim & Não & NA & Tot & Sim & Não & NA & Tot & Sim & Não & NA & Tot \\
\hline \multicolumn{25}{|l|}{ 1.EDIFICAÇÕES E INSTALAÇÕES } \\
\hline 1.1 Área Externa & 2 & & & 2 & 2 & & & 2 & 2 & & & 2 & 2 & & & 2 & 2 & & & 2 & 2 & & & 2 \\
\hline 1.2 Acesso & 1 & & & 1 & 1 & & & 1 & 1 & & & 1 & 1 & & & 1 & 1 & & & 1 & 1 & & & 1 \\
\hline 1.3 Área Interna & 1 & & & 1 & 1 & & & 1 & 1 & & & 1 & 1 & & & 1 & 1 & & & 1 & 1 & & & 1 \\
\hline 1.4 Piso & & 2 & 1 & 3 & & 2 & 1 & 3 & 2 & & 1 & 3 & 1 & 1 & 1 & 3 & & 2 & 1 & 3 & 2 & & 1 & 3 \\
\hline 1.5 Tetos & & 2 & & 2 & & 2 & & 2 & 2 & & & 2 & 1 & 1 & & 2 & & 2 & & 2 & 2 & & & 2 \\
\hline 1.6 Paredes & & 3 & & 3 & & 2 & 1 & 3 & 3 & & & 3 & 1 & 1 & 1 & 3 & & 3 & & 3 & 2 & & 1 & 3 \\
\hline 1.7 Portas & & 3 & & 3 & & 3 & & 3 & & & 3 & 3 & 1 & 2 & & 3 & & 3 & & 3 & 2 & & 1 & 3 \\
\hline 1.8 Janelas & 1 & 2 & & 3 & & 1 & 2 & 3 & & 2 & 1 & 3 & & & 3 & 3 & 1 & 2 & & 3 & & & 3 & 3 \\
\hline 1.9 Escadas & & & 2 & 2 & 2 & & & 2 & 2 & & & 2 & & 2 & & 2 & & 2 & & 2 & & & 2 & 2 \\
\hline 1.10 Instalações Sanitárias P/Manipuladores & 4 & 10 & 1 & 15 & 4 & 10 & 1 & 15 & & 3 & 12 & 15 & 5 & 9 & 1 & 15 & 5 & 10 & & 15 & & & 15 & 15 \\
\hline 1.11 Instalações Sanitárias P/Visitantes & 1 & & & 1 & 1 & & & 1 & 1 & & & 1 & 1 & & & 1 & 1 & & & 1 & 1 & & & 1 \\
\hline 1.12 Lavatórios & & 2 & & 2 & & 1 & 1 & 2 & 2 & & & 2 & 2 & & & 2 & & 2 & & 2 & & 1 & 1 & 2 \\
\hline 1.13 Iluminação e Instalação Elet. & 2 & 1 & & 3 & 1 & 2 & & 3 & 2 & 1 & & 3 & 1 & 2 & & 3 & 2 & 1 & & 3 & 2 & 1 & & 3 \\
\hline 1.14 Ventilação e Climatização & 1 & 6 & & 7 & 1 & 6 & & 7 & 1 & & 6 & 7 & & 2 & 5 & 7 & 1 & 6 & & 7 & & 2 & 5 & 7 \\
\hline 1.15 Higiene das Instalações & 6 & 2 & 1 & 9 & 8 & 1 & & 9 & 7 & 1 & 1 & 9 & 8 & 1 & & 9 & 6 & 2 & 1 & 9 & 4 & 1 & 4 & 9 \\
\hline 1.16 Controle Vetores & 3 & & & 3 & 3 & & & 3 & & & 3 & 3 & 3 & & & 3 & 3 & & & 3 & 2 & & 1 & 3 \\
\hline 1.17 Abastecimento de Água & & & 10 & 10 & & & 10 & 10 & & & 10 & 10 & & & 10 & 10 & & & 10 & 10 & & & 10 & 10 \\
\hline 1.18 Manejo de Resíduos & 1 & 2 & & 3 & 1 & 2 & & 3 & 1 & 1 & 1 & 3 & 3 & & & 3 & 1 & 2 & & 3 & 1 & 1 & 1 & 3 \\
\hline 1.19 Esgotamento Sanitário & & & 1 & 1 & & & 1 & 1 & & & 1 & 1 & & & 1 & 1 & & & 1 & 1 & & & 1 & 1 \\
\hline 1.20 Leiaute & 2 & & & 2 & 1 & 1 & & 2 & 2 & & & 2 & 1 & & 1 & 2 & 2 & & & 2 & 1 & 1 & & 2 \\
\hline TOTAL & 25 & 35 & 16 & 76 & 26 & 33 & 17 & 76 & 29 & 8 & 39 & 76 & 32 & 21 & 23 & 76 & 26 & 37 & 13 & 76 & 23 & 7 & 46 & 76 \\
\hline
\end{tabular}




\begin{tabular}{|c|c|c|c|c|c|c|c|c|c|c|c|c|c|c|c|c|c|c|c|c|c|c|c|c|}
\hline 2. EQUIP.MÓVEIS E UTENSÍLIOS & & & & 0 & & & & 0 & & & & 0 & & & & 0 & & & & 0 & & & & 0 \\
\hline 2.1 Equipamentos & 4 & 4 & & 8 & 1 & 6 & 1 & 8 & & 4 & 4 & 8 & 4 & 3 & 1 & 8 & 4 & 4 & & 8 & 1 & 4 & 3 & 8 \\
\hline 2.2 Móveis & & 2 & & 2 & 1 & 1 & & 2 & 2 & & & 2 & 1 & 1 & & 2 & & 2 & & 2 & & & 2 & 2 \\
\hline 2.3 Utensílios & & 2 & & 2 & 1 & 1 & & 2 & 2 & & & 2 & 2 & & & 2 & & 2 & & 2 & 1 & 1 & & 2 \\
\hline 2.4 Higiene dos Equipamentos e Máquinas & 4 & 3 & 2 & 9 & 8 & 1 & & 9 & 8 & 1 & & 9 & 8 & 1 & & 9 & 4 & 3 & 2 & 9 & 7 & 1 & 1 & 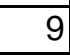 \\
\hline TOTAL & 8 & 11 & 2 & 21 & 11 & 9 & 1 & 21 & 12 & 5 & 4 & 21 & 15 & 5 & 1 & 21 & 8 & 11 & 2 & 21 & 9 & 6 & 6 & 21 \\
\hline 3. MANIPULADORES & & & & 0 & & & & 0 & & & & 0 & & & & 0 & & & & 0 & & & & \\
\hline 3.1 Vestuário & 3 & & & 3 & 3 & & & 3 & 3 & & & 3 & 3 & & & 3 & 3 & & & 3 & 3 & & & 3 \\
\hline 3.2 Hábitos Higiênicos & & 1 & 2 & 3 & 1 & 1 & 1 & 3 & 2 & & 1 & 3 & 2 & 1 & & 3 & & 1 & 2 & 3 & & 1 & 2 & 3 \\
\hline 3.3 Estado de Saúde & & & 1 & 1 & 1 & & & 1 & 1 & & & 1 & 1 & & & 1 & & & 1 & 1 & 1 & & & 1 \\
\hline 3.4 Prog. De Controle da Saúde & & 2 & & 2 & & 2 & & 2 & & 2 & & 2 & 1 & 1 & & 2 & & 2 & & 2 & & 2 & & 2 \\
\hline 3.5 Equip. de Proteção Individual & & & 1 & 1 & & & 1 & 1 & & & 1 & 1 & & & 1 & 1 & & & 1 & 1 & & & 1 & 1 \\
\hline 3.6 Prog. de Capacitação p/ Manipuladores & 4 & & & 4 & & 3 & 1 & 4 & 4 & & & 4 & 2 & 2 & & 4 & 4 & & & 4 & 2 & 1 & 1 & 4 \\
\hline TOTAL & 7 & 3 & 4 & 14 & 5 & 6 & 3 & 14 & 10 & 2 & 2 & 14 & 9 & 4 & 1 & 14 & 7 & 3 & 4 & 14 & 6 & 4 & 4 & 14 \\
\hline 4. PRODUÇÃO E TRANSP.ALIMENTOS & & & & 0 & & & & 0 & & & & 0 & & & & 0 & & & & 0 & & & & 0 \\
\hline 4.1 Mat. Prima, Ingredientes e Embalagens & & & 11 & 11 & & & 11 & 11 & & & 11 & 11 & 4 & & 7 & 11 & & & 11 & 11 & & & 11 & 11 \\
\hline 4.2 Fluxo de Produção & & & 4 & 4 & & & 4 & 4 & & & 4 & 4 & 1 & 1 & 2 & 4 & & & 4 & 4 & & & 4 & 4 \\
\hline 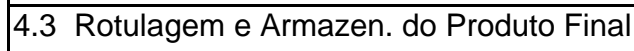 & & & 9 & 9 & & & 9 & 9 & & & 9 & 9 & 3 & 2 & 4 & 9 & & & 9 & 9 & & & 9 & 9 \\
\hline 4.4 Controle de Qualidade do Produto Final & & & 4 & 4 & & & 4 & 4 & & & 4 & 4 & & & 4 & 4 & & & 4 & 4 & & & 4 & 4 \\
\hline 4.5 Transporte do Produto Final & & & 5 & 5 & & & 5 & 5 & & & 5 & 5 & & & 5 & 5 & & & 5 & 5 & & & 5 & 5 \\
\hline TOTAL & 0 & 0 & 33 & 33 & 0 & 0 & 33 & 33 & 0 & 0 & 33 & 33 & 8 & 3 & 22 & 33 & 0 & 0 & 33 & 33 & 0 & 0 & 33 & 33 \\
\hline 5. DOCUMENTAÇÃO & & & & 0 & & & & 0 & & & & 0 & & & & 0 & & & & 0 & & & $\mathrm{x}$ & 0 \\
\hline 5.1 Manual de BPF & & & 1 & 1 & & 1 & & 1 & 1 & & & 1 & 1 & & & 1 & & & 1 & 1 & & & 1 & 1 \\
\hline $5.2 \mathrm{POP}$ & & 16 & 8 & 24 & & 16 & 8 & 24 & & 16 & 8 & 24 & 3 & 13 & 8 & 24 & & 16 & 8 & 24 & & 16 & 8 & 24 \\
\hline TOTAL & 0 & 16 & 9 & 25 & 0 & 17 & 8 & 25 & 1 & 16 & 8 & 25 & 4 & 13 & 8 & \begin{tabular}{|l|}
25 \\
\end{tabular} & 0 & 16 & 9 & 25 & 0 & 16 & 9 & 25 \\
\hline
\end{tabular}




\begin{tabular}{|c|c|c|c|c|c|c|c|c|}
\hline \multirow{3}{*}{$\begin{array}{l}\text { ITENS DO MANUAL DE BOAS PRÁTICAS } \\
\text { DE FABRICAÇÃO }\end{array}$} & \multicolumn{8}{|c|}{ RESTAURANTES PESQUISADOS } \\
\hline & \multicolumn{4}{|c|}{$\mathrm{G}$} & \multicolumn{4}{|c|}{$\mathrm{H}$} \\
\hline & $\operatorname{sim} 11$ & Não & NA & Tot & Sim & Não & NA & Tot \\
\hline \multicolumn{9}{|l|}{ 1.EDIFICAÇÕES E INSTALAÇÕES } \\
\hline 1.1 Área Externa & 2 & & & 2 & 2 & & & 2 \\
\hline 1.2 Acesso & 1 & & & 1 & 1 & & & 1 \\
\hline 1.3 Área Interna & 1 & & & 1 & 1 & & & 1 \\
\hline 1.4 Piso & 3 & & & 3 & 3 & & & 3 \\
\hline 1.5 Tetos & 2 & & & 2 & 2 & & & 2 \\
\hline 1.6 Paredes & 3 & & & 3 & 2 & 1 & & 3 \\
\hline 1.7 Portas & & 1 & 2 & 3 & 3 & & & 3 \\
\hline 1.8 Janelas & 1 & 1 & 1 & 3 & 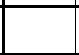 & & 3 & 3 \\
\hline 1.9 Escadas & 2 & & & 2 & 2 & & & 2 \\
\hline 1.10 Instalações Sanitários P/Manipuladores & 5 & 4 & 6 & 15 & 9 & 5 & 1 & 15 \\
\hline 1.11 Instalações Sanitárias P/Visitantes & 1 & & & 1 & 1 & & & 1 \\
\hline 1.12 Lavatórios & & 1 & 1 & 2 & 2 & & & 2 \\
\hline 1.13 lluminação e Instalação Elétricas & & 1 & 2 & 3 & 2 & 1 & & 3 \\
\hline 1.14 Ventilação e Climatização & 4 & & 3 & 7 & 4 & & 3 & 7 \\
\hline 1.15 Higiene das Instalações & 7 & 2 & & 9 & 8 & 1 & & $\mathrm{~s}$ \\
\hline 1.16 Controle Vetores & 3 & & & 3 & 1 & 1 & 1 & 3 \\
\hline 1.17 Abastecimento de Água & & & 10 & 10 & & & 10 & 10 \\
\hline 1.18 Manejo de Resíduos & 2 & 1 & & 3 & 2 & 1 & & 3 \\
\hline 1.19 Esgotamento Sanitário & & & 1 & 1 & & & 1 & 1 \\
\hline \multirow[t]{3}{*}{1.20 Leiaute } & 1 & 1 & & 2 & 2 & & & 2 \\
\hline & 38 & 12 & 26 & 76 & 47 & 10 & 19 & 76 \\
\hline & & & & 0 & & & & $\mathrm{c}$ \\
\hline 2. EQUIP.MÓVEIS E UTENSÍLIOS & & & & 0 & & & & $\mathrm{c}$ \\
\hline 2.1 Equipamentos & 5 & 3 & & 8 & & 4 & 4 & $\varepsilon$ \\
\hline
\end{tabular}




\begin{tabular}{|c|c|c|c|c|c|c|c|c|}
\hline 2.2 Móveis & 2 & & & 2 & 2 & & & 2 \\
\hline 2.3 Utensílios & 2 & & & 2 & 2 & & & 2 \\
\hline 2.4 Higiene dos Equipamentos e Máquinas & 7 & 1 & 1 & 9 & 8 & & 1 & 9 \\
\hline TOTAL & 16 & 4 & 1 & 21 & 12 & 4 & 5 & 21 \\
\hline 3. MANIPULADORES & & & & 0 & & & & 0 \\
\hline 3.1 Vestuário & 3 & & & 3 & 3 & & & 3 \\
\hline 3.2 Hábitos Higiênicos & 1 & 1 & 1 & 3 & 1 & 1 & 1 & 3 \\
\hline 3.3 Estado de Saúde & & & 1 & 1 & 1 & & & 1 \\
\hline 3.4 Programa de Controle da Saúde & & 2 & & 2 & & 2 & & 2 \\
\hline 3.5 Equipamento de Proteção Individual & & & 1 & 1 & & & 1 & 1 \\
\hline \multirow[t]{3}{*}{ 3.6 Prog. De Capacitação p/ Manipuladores } & 2 & 2 & & 4 & 2 & 2 & & 4 \\
\hline & 6 & 5 & 3 & 14 & 7 & 5 & 2 & 14 \\
\hline & & & & 0 & & & & 0 \\
\hline 4. PRODUÇÃO E TRANSP.ALIMENTOS & & & & 0 & & & & 0 \\
\hline 4.1 Mat. Prima, Ingredientes e Embalagens & & & 11 & 11 & & & 11 & 11 \\
\hline 4.2 Fluxo de Produção & & & 4 & 4 & & & 4 & 4 \\
\hline 4.3 Rotulagem e Armazen. do Produto Final & & & 9 & 9 & & & 9 & 9 \\
\hline 4.4 Controle de Qualidade do Produto Final & & & 4 & 4 & & & 4 & 4 \\
\hline 4.5 Transporte do Produto Final & & & 5 & 5 & & & 5 & 5 \\
\hline TOTAL & 0 & 0 & 33 & 33 & 0 & 0 & 33 & 33 \\
\hline 5. DOCUMENTAÇÃO & & & & 0 & & & & 0 \\
\hline 5.1 Manual de BPF & 1 & & & 1 & 1 & & & 1 \\
\hline $5.2 \mathrm{POP}$ & & 16 & 8 & 24 & & 16 & 8 & 24 \\
\hline TOTAL & 1 & 16 & 8 & 25 & 1 & 16 & 8 & 25 \\
\hline
\end{tabular}


APENDICE 3

BOAS PRÁTICAS DE FABRICAÇÃO - CLASSIFICAÇÃO DOS RESTAURANTES PESQUISADOS

\begin{tabular}{|l|r|r|r|r|}
\hline \multicolumn{1}{|c|}{ Restaurante A / Classificação: Grupo 3 } & Sim & \multicolumn{1}{c|}{ Não } & \multicolumn{1}{|c|}{ NA } & \multicolumn{1}{c|}{ Total } \\
\hline 1.Edificações e Instalações & 25 & 35 & 16 & 76 \\
\hline 2. Equipamentos, Móveis e Utensílios & 8 & 11 & 2 & 21 \\
\hline 3. Manipuladores & 7 & 3 & 4 & 14 \\
\hline 4. Produção e Transporte do alimento & & & 33 & 33 \\
\hline 5. Documentação & & 16 & 9 & 25 \\
\hline Total & 40 & 65 & 64 & 169 \\
\hline$\%$ & 23,7 & 38,462 & 37,87 & 100 \\
\hline
\end{tabular}

\begin{tabular}{|l|r|r|r|r|}
\hline \multicolumn{1}{|c|}{ Restaurante B / Classificação: Grupo 3 } & \multicolumn{1}{c|}{ Sim } & Não & \multicolumn{1}{c|}{ NA } & \multicolumn{1}{c|}{ Total } \\
\hline 1.Edificações e Instalações & 26 & 33 & 17 & 76 \\
\hline 2. Equipamentos, Móveis e Utensílios & 11 & 9 & 1 & 21 \\
\hline 3. Manipuladores & 5 & 6 & 3 & 14 \\
\hline 4. Produção e Transporte do alimento & & & 33 & 33 \\
\hline 5. Documentação & & 17 & 8 & 25 \\
\hline Total & 42 & 65 & 62 & 169 \\
\hline$\%$ & 24,852 & 38,462 & 36,686 & 100 \\
\hline
\end{tabular}

\begin{tabular}{|l|r|r|r|r|}
\hline \multicolumn{1}{|c|}{ Restaurante C / Classificação: Grupo 3 } & Sim & \multicolumn{1}{c|}{ Não } & \multicolumn{1}{c|}{ NA } & \multicolumn{1}{c|}{ Total } \\
\hline 1.Edificações e Instalações & 29 & 8 & 39 & 76 \\
\hline 2. Equipamentos, Móveis e Utensílios & 11 & 9 & 1 & 21 \\
\hline 3. Manipuladores & 10 & 2 & 2 & 14 \\
\hline 4. Produção e Transporte do alimento & & & & 0 \\
\hline 5. Documentação & 1 & 16 & 8 & 25 \\
\hline Total & 51 & 35 & 50 & 136 \\
\hline$\%$ & 37,5 & 25,735 & 36,765 & 100 \\
\hline
\end{tabular}

\begin{tabular}{|l|r|r|r|r|}
\hline \multicolumn{1}{|c|}{ Restaurante D/ Classificação: Grupo 3 } & \multicolumn{1}{c|}{ Sim } & Não & NA & \multicolumn{1}{c|}{ Total } \\
\hline 1.Edificações e Instalações & 32 & 21 & 23 & 76 \\
\hline 2. Equipamentos, Móveis e Utensílios & 15 & 5 & 1 & 21 \\
\hline 3. Manipuladores & 9 & 4 & 1 & 14 \\
\hline 4. Produção e Transporte do alimento & & & & 0 \\
\hline 5. Documentação & 4 & 13 & 8 & 25 \\
\hline Total & 60 & 43 & 33 & 136 \\
\hline$\%$ & 44,118 & 31,618 & 24,265 & 100 \\
\hline
\end{tabular}

\begin{tabular}{|l|r|r|r|r|}
\hline \multicolumn{1}{|c|}{ Restaurante E / Classificação: Grupo 3 } & Sim & \multicolumn{1}{|c|}{ Não } & \multicolumn{1}{|c|}{ NA } & \multicolumn{1}{|c|}{ Total } \\
\hline 1.Edificações e Instalações & 26 & 37 & 13 & 76 \\
\hline 2. Equipamentos, Móveis e Utensílios & 8 & 11 & 2 & 21 \\
\hline 3. Manipuladores & 7 & 3 & 4 & 14 \\
\hline 4. Produção e Transporte do alimento & & & & 0 \\
\hline 5. Documentação & & 16 & 9 & 25 \\
\hline Total & 41 & 67 & 28 & 136 \\
\hline$\%$ & 30,1 & 49,265 & 20,588 & 100 \\
\hline
\end{tabular}

\begin{tabular}{|l|r|r|r|r|}
\hline \multicolumn{1}{|c|}{ Restaurante F / Classificação: Grupo 3 } & \multicolumn{1}{c|}{ Sim } & Não & \multicolumn{1}{c|}{ NA } & \multicolumn{1}{c|}{ Total } \\
\hline 1.Edificações e Instalações & 23 & 7 & 46 & 76 \\
\hline 2. Equipamentos, Móveis e Utensílios & 9 & 6 & 6 & 21 \\
\hline 3. Manipuladores & 6 & 4 & 4 & 14 \\
\hline 4. Produção e Transporte do alimento & & & & 0 \\
\hline 5. Documentação & & 16 & 9 & 25 \\
\hline Total & 38 & 33 & 65 & 136 \\
\hline$\%$ & 27,941 & 24,265 & 47,794 & 100 \\
\hline
\end{tabular}




\begin{tabular}{|l|r|r|r|r|}
\hline \multicolumn{1}{|c|}{ Restaurante G/ Classificação: Grupo 3 } & Sim & \multicolumn{1}{c|}{ Não } & \multicolumn{1}{c|}{ NA } & \multicolumn{1}{c|}{ Total } \\
\hline 1.Edificações e Instalações & 38 & 12 & 26 & 76 \\
\hline 2. Equipamentos, Móveis e Utensílios & 16 & 4 & 1 & 21 \\
\hline 3. Manipuladores & 6 & 5 & 3 & 14 \\
\hline 4. Produção e Transporte do alimento & & & & 0 \\
\hline 5. Documentação & 1 & 16 & 8 & 25 \\
\hline Total & 61 & 37 & 38 & 136 \\
\hline$\%$ & 44,9 & 27,206 & 27,941 & 100 \\
\hline
\end{tabular}

\begin{tabular}{|l|r|r|r|r|}
\hline \multicolumn{1}{|c|}{ Restaurante H / Classificação: Grupo 3 } & \multicolumn{1}{c|}{ Sim } & \multicolumn{1}{c|}{ Não } & \multicolumn{1}{c|}{ NA } & \multicolumn{1}{c|}{ Total } \\
\hline 1.Edificações e Instalações & 47 & 10 & 19 & 76 \\
\hline 2. Equipamentos, Móveis e Utensílios & 12 & 4 & 5 & 21 \\
\hline 3. Manipuladores & 7 & 5 & 2 & 14 \\
\hline 4. Produção e Transporte do alimento & & & & 0 \\
\hline 5. Documentação & 1 & 16 & 8 & 25 \\
\hline Total & 67 & 35 & 34 & 136 \\
\hline$\%$ & 49,265 & 25,735 & 25 & 100 \\
\hline
\end{tabular}

*NA: Não se Aplica

Critérios Para a Classificação: Grupo 1 - de 76 a 100\% de atendimento de todos os itens.

Grupo 2 - de 51 a $75 \%$ de atendimento de todos os itens.

Grupo 3 - de 0 a $50 \%$ de atendimento de todos os itens. 